University of Nebraska - Lincoln

DigitalCommons@University of Nebraska - Lincoln

Publications, Agencies and Staff of the U.S.

Department of Commerce

U.S. Department of Commerce

2008

\title{
Design and field methods for sighting surveys of cetaceans in coastal and riverine habitats
}

\author{
Steve Dawson \\ University of Otago, steve.dawson@stonebow.otago.ac.nz \\ Paul Wade \\ National Marine Mammal Laboratory \\ Elisabeth Slooten \\ University of Otago \\ Jay Barlow \\ National Marine Fisheries Service, jay.barlow@noaa.gov
}

Follow this and additional works at: https://digitalcommons.unl.edu/usdeptcommercepub

Part of the Environmental Sciences Commons

Dawson, Steve; Wade, Paul; Slooten, Elisabeth; and Barlow, Jay, "Design and field methods for sighting surveys of cetaceans in coastal and riverine habitats" (2008). Publications, Agencies and Staff of the U.S. Department of Commerce. 255.

https://digitalcommons.unl.edu/usdeptcommercepub/255

This Article is brought to you for free and open access by the U.S. Department of Commerce at DigitalCommons@University of Nebraska - Lincoln. It has been accepted for inclusion in Publications, Agencies and Staff of the U.S. Department of Commerce by an authorized administrator of DigitalCommons@University of Nebraska - Lincoln. 


\title{
Design and field methods for sighting surveys of cetaceans in coastal and riverine habitats
}

\author{
STEVE DAWSON*, PAUL WADE†, ELISABETH SLOOTEN\$ and \\ JAY BARLOW $\S$ \\ *Department of Marine Science, University of Otago, PO Box 56, Dunedin, New Zealand, \\ $\uparrow$ National Marine Mammal Laboratory, 7600 Sand Point Way NE, Seattle, WA 98115, \\ USA, $\$$ Department of Zoology, University of Otago, PO Box 56, Dunedin, New Zealand, \\ §National Marine Fisheries Service, 8604 La Jolla Shores Drive, CA 92037, USA
}

\begin{abstract}
1. Dolphins and porpoises in coastal and/or riverine habitats face serious conservation threats, yet surveys of their abundance are often especially difficult due to the challenges imposed by the habitats. Because many of these species occur in developing countries, lack of resources imposes a further set of challenges.

2. We offer advice on designing and conducting line-transect surveys with a focus on sound, practical, design rather than analytical sophistication, and we attempt, where possible, to offer simple, inexpensive solutions.

3. We guide the reader through the questions of what kind of survey should be done, whether by boat or aircraft, and we discuss ways to avoid bias and increase precision.

4. Our treatment of field methods focuses especially on robust, but low-cost, approaches. We provide two case studies to illustrate the implementation of these ideas.
\end{abstract}

Keywords: abundance, aerial, boat, dolphin, porpoise, trends

\section{INTRODUCTION}

Data on abundance are among the most basic in ecology and conservation biology. Unfortunately, the simple question of 'how many are there?' can be difficult to answer robustly. That challenge is particularly great for cetaceans in coastal and riverine habitats. Abundance data for these species are sorely needed, for our coasts and rivers suffer greater human impact than any other marine mammal habitat. Several coastal and riverine species are seriously threatened, and one, the Baiji Lipotes vexillifer of China's Yangtze River, is now probably extinct (Turvey et al., 2007). All of the river dolphins suffer from by-catch and habitat loss and fragmentation (Smith \& Smith, 1998). All coastal cetaceans suffer from by-catch in fishing gear (IWC, 1994). Some are seriously impacted by pollution (e.g. beluga Delphinapterus leucas; Muir et al., 1996). Some suffer from direct hunting for bait or human consumption (e.g. dusky dolphins Lagenorhynchus obscurus, Burmeister's porpoise Phocoena spinipinnis; Vidal, 1993; Van Waerebeek et al., 1999), and some suffer from habitat loss due to coastal development (e.g. Indo-Pacific humpback dolphins Sousa chinensis; Jefferson \& Hung, 2004). Impacts of these threats cannot be assessed quantitatively without robust abundance data.

Additionally, abundance data form part of the scientific basis of conservation planning. The need for such data was clearly demonstrated at the January, 2007 IUCN workshop held

Correspondence: S. Dawson. E-mail: steve.dawson@stonebow.otago.ac.nz 
to update and revise the Redlist status of cetaceans. Ten of 21 odontocetes that could be considered coastal or riverine were provisionally classified as 'Data Deficient' - chiefly for lack of abundance or trend data.

While the need for high-quality abundance data is clear, the means of getting them is not. Coastal and riverine habitats are complex and impose many constraints on survey design. Further, because many of these species are found in countries without large budgets for conservation, it would help enormously if survey methods were as inexpensive as possible (Aragones, Jefferson \& Marsh, 1997).

There are two major classes of methods for assessing cetacean abundance: mark-recapture methods in which re-sightings of naturally or artificially marked individuals are used to calculate abundance, and sighting surveys in which animals are counted in order to assess their density (Seber, 1982). Mark-recapture analysis of photo-ID data can provide highly precise estimates of abundance, and has two important advantages over line-transect surveys; photo-ID generally has meagre boat requirements (e.g. no need for a raised sighting platform) and can provide data on a wealth of other biological parameters (Hammond, Mizroch \& Donovan, 1990). In practice, most mark-recapture studies of cetaceans have quantified local populations on relatively small geographical scales (e.g. Gormley et al., 2005). However, several studies have used systematic wide-ranging surveys to estimate abundance for a species using line-transect methods, and then have combined photo-ID data from those surveys with localized photo-ID data collected from small boats to estimate abundance using mark-recapture methods. Examples include humpback whale Megaptera novaeangliae and blue whale Balaenoptera musculus (Calambokidis \& Barlow, 2004) and killer whales Orcinus orca (Zerbini et al., 2007; P. Wade, unpublished data). Mark-recapture methods are, however, less generally applicable than line-transect methods, because they rely on individuals being distinctive and easily photographed. Mark-recapture methods are thus not suitable for many species of coastal and riverine cetaceans.

Here we focus on sighting surveys (Barlow, 1988). General issues relating to line-transect surveys are covered in the new edition of Distance Sampling (Buckland et al., 2001). Further developments in the field can be found in a second volume, Advanced Distance Sampling (Buckland et al., 2004). Our intention is not to cover that ground again, but to concentrate on issues which specifically relate to designing and conducting surveys of inshore or riverine cetaceans. We assume that the reader is familiar with the basics of line-transect sampling. Aragones et al. (1997) provide a useful overview of a variety of marine mammal survey techniques that are applicable in developing countries, including boat and aerial surveys. We focus here on details of design and field methods not covered in that paper.

In this contribution, we emphasize the use of proper survey design to obtain unbiased estimates of cetacean abundance. Recent developments in line-transect theory have allowed analysis of data from poor sampling designs (without equal coverage probability) (Hedley, Buckland \& Borchers, 1999; Buckland et al., 2004) by using spatial modelling methods to develop a model of marine mammal densities within the study area. We do not discuss this advanced topic in detail. Typically, such methods have been applied to data collected from platforms of opportunity (e.g. Williams, Hedley \& Hammond, 2006), from which it was not possible to conduct a well-designed survey. Using data from an aerial sighting survey, Gómez de Segura et al. (2007) compared standard line-transect analysis with an analysis via spatial modelling, finding similar density and variance estimates for both methods. Clearly, modelbased estimation is useful if an equal coverage sighting survey is not possible but detailed environmental data are available, and may have a useful role in analysing data where a good design was intended, but not achieved, perhaps due to environmental factors such as fog, 
rough weather or ice. But it is not a substitute for good survey design. No amount of analytical sophistication can fully compensate for inadequate sampling.

The software package Distance 5.0 has a design module that implements many aspects of good survey design automatically (Strindberg, Buckland \& Thomas, 2004). This excellent feature is not a replacement for understanding the principles of line-transect survey design, and requires a fair amount of sophistication from the user. Distance's design module can be very helpful in evaluating different candidate designs (see Thomas, Sandilands \& Williams, 2007).

Our experience has been that surveys are often designed poorly. We have seen many survey designs that had no chance of providing unbiased, reasonably precise population estimates. We are familiar with many of the pitfalls, having ourselves fallen into them or narrowly missed doing so. In this paper, we aim to help researchers design surveys and avoid fundamental flaws.

\section{WHAT IS THE QUESTION: ABUNDANCE OR TRENDS?}

For any survey it will be important to start by clearly identifying an appropriate major objective, and by prioritizing any additional objectives. A crucial question is whether the need is for an absolute abundance estimate, or an assessment of population trend. Surveys for the former are more difficult to do, as they require quantitative assessment of the 'fraction missed' on the track line (i.e. the proportion of animals not available to, or not counted by, the survey method). Estimates of absolute abundance have the advantage that they facilitate direct calculation of what level of take should be sustainable (e.g. by-catch limits; e.g. Potential Biological Removal [PBR], Wade, 1998). Estimation of trends usually do not involve assessment of the fraction missed, on the assumption that if survey methods are kept constant, the fraction missed should not change systematically (Caughley, 1977). This assumes, however, that the fraction missed does not change due to factors beyond the control of the survey team, which is often unrealistic. For example, cetacean distributions can change substantially in El Niño years (e.g. Gardner \& Chávez-Rosales, 2000). If the fraction missed varies with measurable factors (like Beaufort sea state or cloud cover), a trend analysis can use these covariates to correct for some of the sources of variation in fraction missed (Forney, Hanan \& Barlow, 1991).

Obviously, assessments of trends require repeated surveys. In order to increase the statistical power to detect change, and depending on the expected rate of change, it is often better to conduct intensive surveys at several-year intervals, rather than less survey effort annually. Issues of detecting trends are dealt with in Holt, Gerrodette \& Cologne (1987), Gerrodette (1987), Forney et al. (1991) and Wade \& DeMaster (1999). While there are cases in which surveys have detected declines in abundance, and the detected decline led to conservation actions (e.g. Cook Inlet beluga whale; Hobbs, Rugh \& DeMaster, 2000), it is important to note that the power to detect trends from repeated abundance surveys, even if they were carefully designed, is likely to be very low (Taylor et al., 2007). Very rare species may actually go extinct before a statistically significant trend can be detected (Taylor \& Gerrodette, 1993).

In many cases, the most realistic aim is to obtain a good estimate of absolute abundance and use it to assess the level of human impact on the population using Population Viability Analysis or the PBR approach (Wade, 1998). This approach was taken by Slooten et al. (2006) who showed that there are so few Maui's dolphins Cephalorhynchus hectori maui (111, $\mathrm{cv}=44 \%$ ) that a PBR calculation results in an 'allowable' by-catch of fewer than one dolphin per year. In other words, this abundance survey showed that any by-catch from this population would likely be unsustainable. 


\section{LINE-TRANSECT OR STRIP-TRANSECT?}

Line-transect surveys require measurement of the perpendicular distance from the track line to each sighting. Particularly in small boats, this can be difficult. In strip-transect surveys, animals are counted within a specific distance either side of the track line. Probability of detection is assumed to be one, or at least constant, from the track line out to the edge of the strip. These assumptions are not realistic in most surveys of marine mammals. In analysis of line-transect surveys, a curve is fitted to the observed detection distances in order to estimate effective strip width (Buckland et al., 2001). Hence, in line-transect surveys strip width is not assumed, but empirically estimated from the sighting data. Line-transect techniques have the further advantage of maximizing sample size, because sightings outside the strip width are not ignored (as they are in strip-transect surveys). For these reasons, line-transect methodology is considered superior for cetacean surveys, and strip-transect methods are recommended only in special cases. For example, strip-transects were used to supplement a line-transect survey of river dolphins in the Amazon because of stratification of a very narrow strip along the river banks (see case study 2; Vidal et al., 1997).

\section{SURVEY PLATFORM - AIRCRAFT OR BOAT?}

Coastal line-transect surveys can be carried out using aircraft or boats. Aircraft, because of their speed [typically but not necessarily $90-100$ knots $(167-185 \mathrm{~km} / \mathrm{h})$ ], can cover large areas in a short period, and for this reason might be favoured in regions with short periods of suitable weather. They are not prone to causing responsive movement in the animals surveyed (Buckland et al., 2001). Also, the steeper angles to sightings allow for more accurate measurement of sighting distances than is usually possible from boats. Due to limited seating in aircraft, there is usually less opportunity to rotate or rest observers in order to combat fatigue. Boats, because they travel more slowly (typically $\leq 10$ knots) allow more time for an animal to surface, and therefore boat surveys typically count a much larger proportion of the population. Additionally, boats more easily facilitate collection of other data (e.g. oceanographic, photo-ID and genetic data) while the survey is in progress. Boat surveys are usually less expensive per unit time, but because they take longer for the same amount of coverage, they can work out to be considerably more expensive overall, especially for larger boats or ships. Also, they often cause responsive movement (see below). Issues of survey design are similar for both.

\section{Choice of boat}

A very wide range of boats can be used for line-transect surveys, though some are much more suitable than others. Increasing observer height increases the resolution with which observers can measure the downward angle to sightings, allows observers to see animals further away (lessening the chance of responsive movement) and increases the sightability of the animals (less chance of a sighting being hidden by a wave). For these reasons, boats used for line-transect surveys should have an elevated sighting platform. A 'tuna tower' or similar platform is ideal, and can be designed to be temporary and/or collapsible. For example, we have used a sighting platform on a sailing vessel that could be erected or dismantled (to allow the boat to sail) in less than $10 \mathrm{~min}$ (Fig. 1). Platform height needs to be a compromise: if too high, platform movement due to sea conditions will make it difficult for observers to measure distances, especially if they use binoculars. To minimize effects of pitching, the ideal platform would be mounted towards the stern, rather than amidships, assuming that visibility forward is not obstructed.

Open ocean line-transect surveys typically use ships of between 50- and 70-m length. Due to the damping effect of size, they offer greater inherent stability than smaller vessels. For 
Fig. 1. Examples of small vessels used in coastal and riverine line-transect surveys. Note the raised sighting platforms, which give eye heights between 4.5 and $6 \mathrm{~m}$.
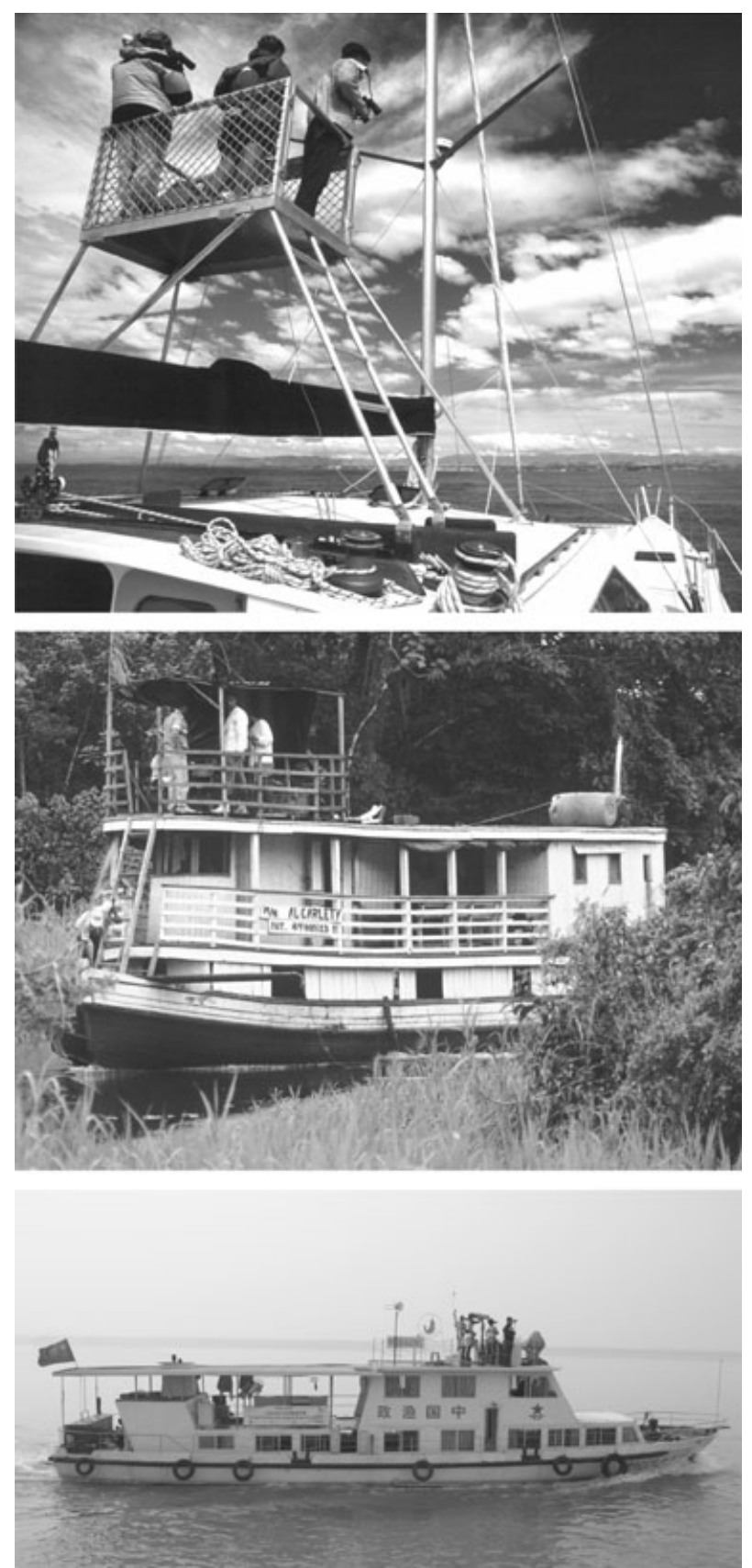

many surveys, however, large vessels are prohibitively expensive to run, and because of their draught and limited maneuverability, they are unsuitable for many inshore surveys. Depending on sea conditions, high-quality line-transect data can be collected from vessels as small as 6-8 $\mathrm{m}$, though the $10-$ to $20-\mathrm{m}$ size range is probably ideal. Because of their resistance to rolling motion, catamarans can be very suitable. Catamarans are capable of higher cruising speeds with less horsepower than typical displacement monohulls of similar length, and this 
makes them economical survey platforms. The narrowness of the hulls can make catamarans more sensitive to pitching, but in practice this can be minimized by steaming survey lines down-swell. This was done whenever necessary in line-transect surveys of Hector's dolphin Cephalorhynchus hectori (Dawson et al., 2004).

Most line-transect surveys from boats are conducted at between 8 and 10 knots (15$18.5 \mathrm{~km} / \mathrm{h}$ ). The upper end of this range is usually governed by the boat's capability. Boat speed should be at least 2-3 times faster than the typical average speed of the animals, or a positive bias may result (Hiby, 1982). Travelling too fast will result in fewer sightings as there will be less time for animals to surface within viewing range. We are not aware of successful cetacean boat surveys carried out at speeds greater than $\sim 14$ knots.

Vessel cost is a very important criterion, because several of the most threatened small cetaceans occur in countries without generous funding for marine mammal research. In addition to facilitating survey work with limited budgets, low-cost vessels allow (i) much more survey effort to be expended for the same cost; (ii) surveys to be conducted in better sighting conditions (since vessel costs are low, you can afford to wait); and (iii) a significant amount of vessel time to be spent on observer training. The probability of detecting an animal of interest on the track line, which in line-transect jargon is known as $g(0)$, combines both availability bias and perception bias. Various methods are used to correct for these biases, including the use of an independent observer team on the same platform. The method(s) chosen will necessarily influence the selection of an appropriate aircraft or boat.

\section{Choice of aircraft}

The primary aircraft requirements for line-transect surveys have to do with visibility, safety and running cost. Because observers must have an unobstructed view of the water, high-wing aircraft are inherently suitable. Additionally, it is very important that observers can see the track line (i.e. directly under the aircraft). Bubble windows, which can be fitted to many aircraft, are sometimes sufficient for this, but a belly window is a better option if available (ideally one would have both). Many line-transect surveys have been done without the ability to see the track line. For this to work, the sighting data must be left-truncated (Buckland et al., 2001) by deciding on a distance at which detection is believed to be maximal and fitting the detection function only to data beyond that distance. This process is necessarily arbitrary, and should be avoided if possible by choosing aircraft from which the track line can be seen.

Safety during aerial surveys is a crucial requirement. We are aware of several fatal crashes on aerial surveys. Causes have included water in the fuel, running out of fuel, and gross handling errors by the pilot. While we are not aware of any aerial survey crashes caused by engine failure, we prefer to use twin-engine aircraft to minimize the consequences of engine malfunction. If survey plans call for occasional circling over sightings (e.g. for species identification), an aircraft with a relatively slow stall speed is desirable. It is worthwhile remembering that key requirements of aerial surveys, specifically the need to fly at low altitude (500 feet is typical) and at relatively slow airspeeds ( $90-100$ knots), inevitably involve some risk and leave little margin for error. All observers need to understand this.

Twin engine aircraft that meet these requirements, and which are often used on aerial surveys, include the six seater Partenavia P-68 (especially the Observer model with an unrestricted view forward), Aero Commander (including the standard model, Shrike and Turbo Commander), Cessna Skymaster and the much larger Dehavilland Twin Otter. Helicopters can be extremely useful, particularly for helping to assess the fraction of sightings missed on the track line (see later). They are, however, usually too expensive to use as a primary survey platform. 
Methods for assessing the fraction missed are covered later, but it is worth pointing out that some methods impose specific aircraft requirements. For example, a belly window is required to assess perception bias (the proportion of sightings that were available to be seen but missed due to fatigue, momentary inattention, glare, etc.) via independent observation of the track line (e.g. Forney, Barlow \& Carretta, 1995). A six-seater aircraft is required if perception bias is to be assessed via comparison of sightings made by two independent teams of observers (e.g. Slooten, Dawson \& Rayment, 2004).

\section{SURVEY DESIGNS}

Two recent papers by Strindberg et al. (2004) and Thomas et al. (2007) have provided much more guidance on survey design issues than was available previously. Inevitably, some of what is below is also covered by them. Here we focus particularly on issues we see as being important for surveys of inshore and riverine cetaceans.

Before starting a survey, it is crucial to define the study area. The abundance estimate derived will apply only to the study area, so it is important to delineate this area precisely. In addition, we should ensure that:

- The area chosen is relevant to any management goals, e.g. the location and size of a proposed or existing protected area.

- The area is biologically relevant, containing the typical movement range of the population at that time of year, or a substantial part of it.

- Practicalities are considered; for example, the study area is not too large to cover within the time available, and the vessel choice suits the area to be surveyed.

\section{LAYING OUT TRANSECT LINES}

The transect lines must represent a random sample of all the habitat area in the survey block. An important principle to bear in mind is that any patch of water within the survey block should have an equal chance of being surveyed - this is termed 'equal coverage probability'. Transect lines could be fully randomized with respect to location and orientation, but this will rarely be practical, because it will result in a large amount of travel time between transects and will often lead to directions of travel that are impractical because of glare or swell direction. Even in a parallel line survey, lines could be spaced at random distances apart to achieve fully random sampling. Recent simulation studies, overlaying different survey designs on a spatially realistic model of an inshore dolphin population, showed that random line spacing had no clear advantage in reducing bias, and systematic line spacing resulted in better precision (DuFresne, Fletcher \& Dawson, 2006).

It is important to remember that the transect lines only have to be random with respect to the animal's distribution and to provide equal coverage probability. Practically, it is useful to combine a random start with regular line spacing within survey blocks. One way to do this is to draw an imaginary baseline along the coast, and plot the start of the first transect at a random point along that baseline (Fig. 2, also see Appendix for details). Thereafter, the other transect lines can be spaced at regular intervals according to the sampling intensity required. The subsequent lines could be described as pseudo-random, but this is only likely to be a problem if the spatial aggregation of animals, by bad luck, coincides with the transect spacing. Therefore, in most cases it will be most practical to lay out a regular pattern of transect lines, but with a randomized starting location.

Regular spacing of lines (whether parallel or zigzag) offers several other advantages over random line spacing. Visual interpretation of spatial distribution is easier, and the data are ideal for contouring density, as long as the sampling intensity and sighting rate are 


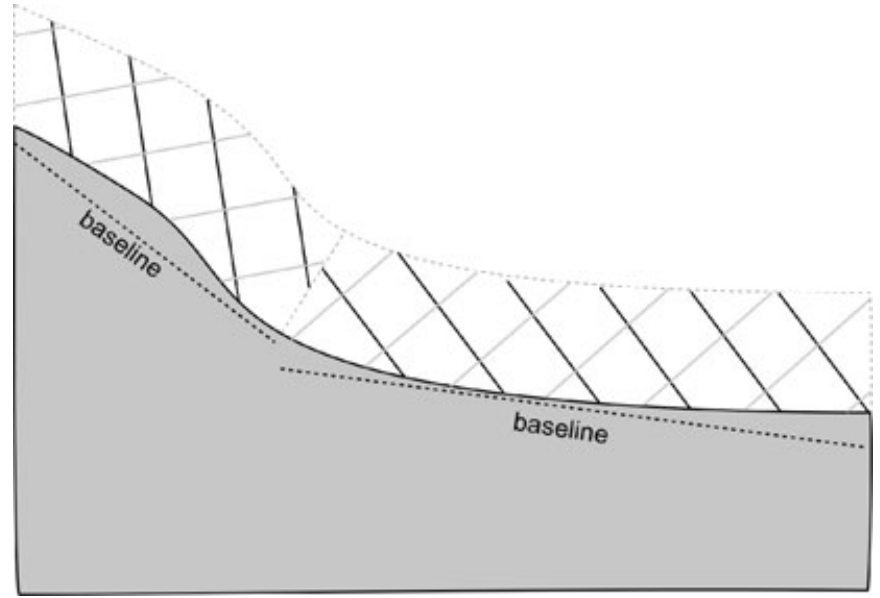

Fig. 2. Where there are gradients in offshore and alongshore distribution, transects at $45^{\circ}$ can be a good solution. In this case, the coast is divided into blocks, a baseline is drawn approximately parallel to the coastline in each block, and equally spaced lines drawn at $45^{\circ}$ to the baseline. The first line in each block is drawn at a random point along the baseline, and the others drawn at a constant spacing with respect to it. The grey $45^{\circ}$ lines are an alternate set that would be used if conditions (e.g. swell, glare) favoured them.

appropriate to the scale of the contours. Also, it is easier to post-stratify the data into particular areas, and hence calculate abundance in a particular sub-area. Regular spacing may also make it easier to examine distribution in relation to shore or depth or other correlates.

\section{Orientation of lines relative to density gradients}

Sampling theory suggests that transect lines should be orientated perpendicular to the contour lines of any known gradients. This is done to avoid bias and to minimize the variance in encounter rate, which will be high if many transects have no or few sightings, while a few transects have many sightings. In particular, this is crucial if the gradient in the density of animals changes more rapidly than the distance between transect lines. Many coastal cetaceans show a density gradient from high density nearshore to low density offshore, so transect lines perpendicular to shore will be preferred over lines parallel to shore. Many cetaceans also show a density gradient alongshore, so transect lines at a $45^{\circ}$ angle to shore will be a good scheme for sampling distributions that vary both alongshore and inshore/offshore (Fig. 2).

\section{Zigzags or parallel transects?}

Boat surveys are usually affected by glare and swell. Boat motion will be most stable running down-swell, and observers will be ineffective looking into glare. For this reason, zigzag designs, while they minimize travel time between transects, may be impractical (especially in small boats). Surveys using small fast boats can minimize travel time between transects by increasing speed. Glare is only really a problem if it is close to the track line. However, zigzag designs mean that the swell and glare conditions may be very different on the different legs of the survey and may compromise observer efficiency for a substantial part of the survey. A survey design that avoids this problem involves laying out two sets of parallel lines at $45^{\circ}$ to the shore, each set at $90^{\circ}$ to each other within each survey block (e.g. Fig. 2). Each survey day, you can choose which set to do, in which direction, so as to minimize effects of swell and glare. In this approach, it is helpful to set block size so that the whole block can be completed 

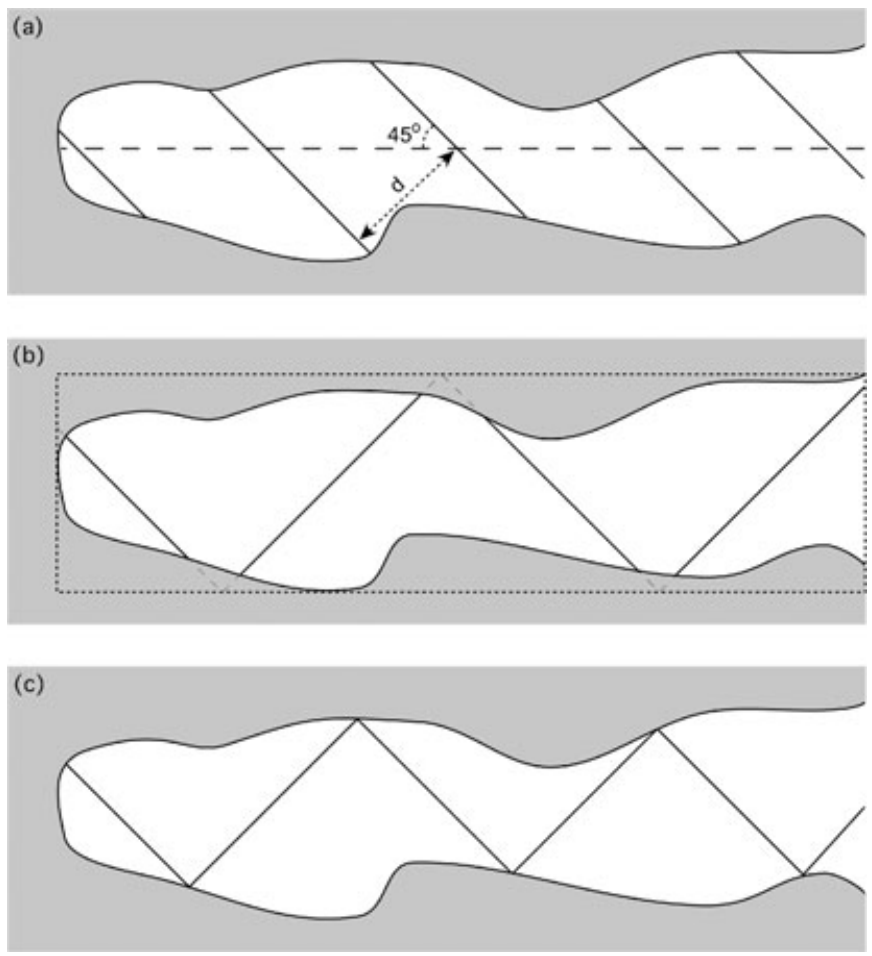

Fig. 3. Two alternate (a \& b), equal coverage schemes for laying out transect lines in a long, narrow inlet. In (a) equally spaced lines are drawn at $45^{\circ}$ to a line down the centre of the inlet. In (b) zigzags are drawn within a box bounding the inlet. As drawn (a) and (b) represent approximately equivalent survey effort. Designs in which the zigzags reflect off the coast (c) are undesirable (see text).

in a sampling day. Changing line orientation after a block is partly covered will result in unequal coverage.

Surveys in very confined waters pose special difficulties. While it might be efficient to travel down the centre of a harbour, fiord or channel, doing so is usually inappropriate as it will almost always result in unequal coverage probability of all the confined waters. If the animals of interest are concentrated in the centre or at the edges, the sampling can be particularly biased. A better approach is to draw an imaginary line down the channel's centre, and place transect lines at $45^{\circ}$ to that centre line (Fig. 3a).

It can be more difficult to achieve equal coverage probability in a zigzag design. An alternative that we recommend is to draw zigzags bounded by a box outside the shoreline (see Fig. 3b), rather than reflecting off the shore itself (Fig. 3c). This approach is relatively easy to design and implement, and provides equal coverage probability. It leaves gaps between transect lines, but these gaps can be beneficial in avoiding problems that can occur at the apexes of zigzag surveys (see discussion below). A design with a constant angle (Fig. 3c), though commonly used, is flawed. Unless the shores are parallel, the coverage will be non-uniform. Other zigzag sampling schemes, and related issues, are described in more detail in Strindberg \& Buckland (2004), Buckland et al. (2004) and Thomas et al. (2007).

In their layout, both schemes a and b (Fig. 3) should have random start points. In (a), an easy way to do this is to randomly select a point on the imaginary line down the centre of the inlet, and draw the first line crossing this point. The other lines are then regularly spaced from 


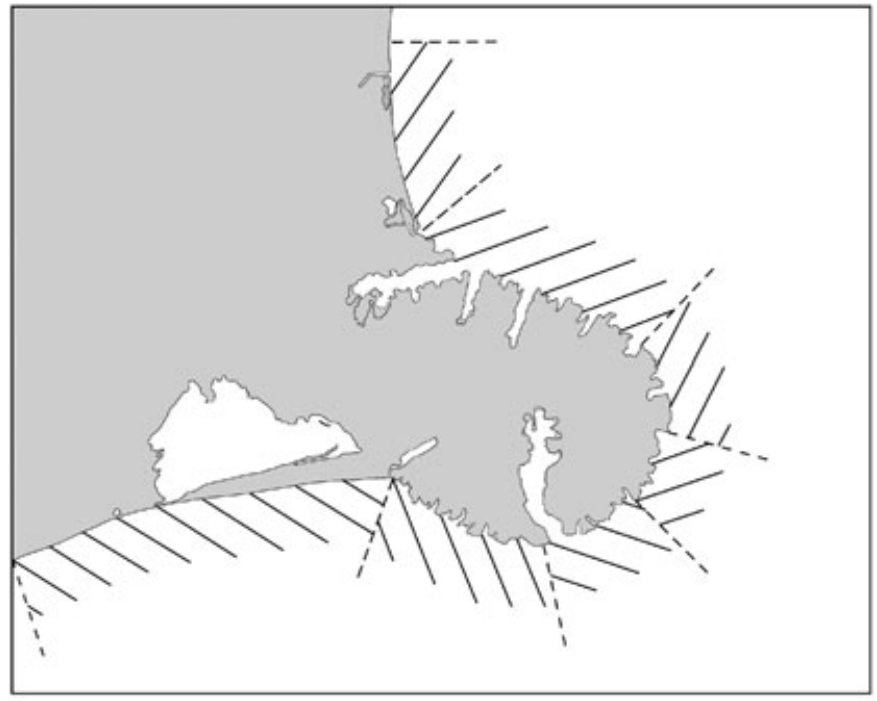

Fig. 4. An example of using survey blocks and randomised $45^{\circ}$ lines to achieve an equal coverage survey design for Hector's dolphins at Banks Peninsula, New Zealand. The transect lines extend to $4 \mathrm{n}$ mile offshore and, within each block, are $2 \mathrm{n}$ mile apart.

this line. In (b) the zigzag lines could be drawn starting from a random point on a line drawn across the entrance of the inlet. In either design, there is no reason why they should not be replicated (ideally with different lines) to increase sample size and precision.

Zigzag survey designs are efficient, as they allow the survey to be more continuously 'on effort', but are most practical along relatively straight coasts or in open water. Line layout on curved or convoluted coasts should not follow the coast. If a zigzag design were laid out around a peninsula, for example, the outer apexes of the zigzags would be further apart than the inner ones. This would result in less effort offshore than inshore, and would be a biased design. This problem is even more obvious in designs using lines orientated directly offshore - these would splay out like the spokes of a wheel. Using parallel lines helps avoid the problem, but better still is to break the curved coastline into several blocks, and draw the parallel lines within the blocks (Fig. 4). In any scheme using parallel lines, it can be advantageous to allow a certain amount of course deviation on any one line (e.g. $\left.10^{\circ}\right)$ to minimize rolling, pitching and/or glare. Ideally, this course change would be applied to all the lines within a sample block.

The apexes of zigzags present some potential problems. Sightings made at the end of one leg may be made again at the start of the next. Additionally, having recently made a sighting near an apex, an observer might subconsciously bias his/her sighting effort on the next leg. Apexes also present opportunities for responsive movement (if the target species either is attracted to or avoids the survey vessel) to bias encounter rates on the start of the next leg. Scheme (b) (Fig. 3) minimizes these problems because the apexes are not surveyed. Another important issue with zigzags is that if there is any significant swell or glare, one leg or the other will have very different sighting conditions. Therefore, it is preferable to steam in one direction only. In many small boat surveys, zigzag survey routes are not practical.

\section{Survey blocks}

Often, it is useful to break the study area into smaller survey blocks. Blocks are not necessarily the same as strata - they are usually smaller. Advantages of blocking include: 
1. To make laying out transect lines easier or more efficient and to ensure even coverage of sampling effort within strata.

2. To deal with complex shorelines (e.g. peninsulas, bays, harbours, fiords) so that oversampling or under-sampling part of the area is avoided.

3. To better accommodate environmental conditions. For example, in an area where bathymetry or coastal topography create localized swell or wind effects, the orientation of lines can be adjusted within this block to minimize the problem, yet retained at a standard orientation elsewhere.

4. To allow for estimation of separate detection functions if part of the study area involves enclosed waters where land prevents the full detection width from being available.

5. To accommodate an offshore boundary that is determined by distance from shore, or depth.

6. To facilitate calculation of an abundance/density estimate for a sub-area of special management or scientific interest (e.g. for Akaroa Harbour in Dawson et al., 2004).

Blocks surveyed at the same intensity of effort (equal effort per unit area) can be pooled for analysis (methods for accomplishing this are summarized in the Appendix). If blocks are surveyed at different intensities, the survey will have a stratified design, and density estimates must be computed for each stratum. The pros and cons of stratification are considered later.

The size of the study area, and of any strata used, must be measured. Usually, this is done using a planimeter or grid system on high-resolution charts or, increasingly, via GIS or other software ${ }^{1}$. This facility is also available in Distance 5.0. Areas that cannot be surveyed (too shallow, etc.) should be excluded from the area measurement.

\section{STRATIFICATION (DIFFERENT INTENSITY OF EFFORT FOR DIFFERENT SURVEY BLOCKS)}

There are three main reasons to consider stratifying a survey. The first is that if one knows ahead of time that there are more animals in one part of the study area, and fewer animals in another, one can achieve greater precision in the total abundance estimate by allocating more effort per unit area to the high-density zone. Second, stratification can allow for areas that have different sighting conditions. For example, if the surveyed area includes protected bays/inlets as well as open coasts, the sighting conditions between these two types of habitat are likely to be different. If so, it may be most appropriate to estimate a separate detection function for each of the two major habitat types (e.g. Dawson et al., 2004). Additionally, if in confined waters the land cuts off the full potential detection width, this will narrow the detection function; this is acceptable if a separate detection function is calculated for that area. Third, stratification can more easily allow generation of abundance estimates for particular areas for management interest (e.g. to match areas used in fisheries management in order to allow easier comparison with fishing effort data), although this can also be accomplished through the creation of separate survey blocks, as discussed above.

A simple, unstratified design is probably favoured when uncertain about future areas of interest (e.g. stock boundaries, future protected areas), or when differences in density are small (DuFresne et al., 2006).

\footnotetext{
${ }^{1}$ Software for this purpose is freely available for Linux, Mac OS (9 and X) and Windows. e.g. ImageJ (http://rsb.info.nih.gov/ij/) can import a map on which a study area is drawn. Following a simple calibration process, area can be calculated automatically. See also Table 1. Be aware that different projections in GIS software can affect area calculations.
} 
Table 1. Free software for recording data on line-transect surveys, designing surveys and analysing line-transect data

\begin{tabular}{|c|c|c|c|}
\hline Name & Operating system & Functions & Available from \\
\hline Distance & $\begin{array}{l}\text { Windows } 95,98 \\
\text { 2000, NT }\end{array}$ & $\begin{array}{l}\text { Survey design, } \\
\text { analysing data }\end{array}$ & http://www.ruwpa.st-and.ac.uk/distance/ \\
\hline Wintrak & $\begin{array}{l}\text { Windows } 95,98 \\
\text { 2000, NT }\end{array}$ & $\begin{array}{l}\text { Designing cruise } \\
\text { tracks, calculating } \\
\text { coverage }\end{array}$ & http://swfsc.noaa.gov/prd.aspx \\
\hline GeoArea & $\begin{array}{l}\text { Windows } 95,98 \\
\text { 2000, NT }\end{array}$ & $\begin{array}{l}\text { Calculating study } \\
\text { areas }\end{array}$ & http://swfsc.noaa.gov/prd.aspx \\
\hline WinCruz & $\begin{array}{l}\text { Windows } 95,98 \\
\text { 2000, NT }\end{array}$ & $\begin{array}{l}\text { Data entry and } \\
\text { track recording } \\
\text { for boat surveys }\end{array}$ & http://swfsc.noaa.gov/prd.aspx \\
\hline Logger, 2000 & $\begin{array}{l}\text { Windows } 95,98 \\
\text { 2000, NT }\end{array}$ & $\begin{array}{l}\text { Data entry and } \\
\text { track recording. } \\
\text { Customisable for } \\
\text { manual data input }\end{array}$ & $\begin{array}{l}\text { http://www.ifaw.org/ifaw/general/ } \\
\text { default.aspx?oid=25653 }\end{array}$ \\
\hline Airtrack & DOS & $\begin{array}{l}\text { Data entry and } \\
\text { track recording } \\
\text { for aerial surveys }\end{array}$ & http://www.otago.ac.nz/marinescience/ \\
\hline L-Tsurv & DOS & $\begin{array}{l}\text { Data entry and } \\
\text { track recording } \\
\text { for boat surveys }\end{array}$ & http://www.otago.ac.nz/marinescience/ \\
\hline
\end{tabular}

For software available from SWFSC, follow the 'Data portal and software' link (several other useful programmes are also available here). Airtrack and $L$-Tsurv are optimized for HP200LX palmtop computers.

Coastal habitats are much more complex than the open ocean, and may have areas with very different sighting conditions, or areas of particular management significance. Hence, while open ocean surveys are often unstratified, using randomly generated transect lines, allocating survey effort according to a geographical stratification scheme is often desirable in coastal or riverine surveys. Even coverage within strata is crucial, and helps minimize biases due to patchiness or geographical trends in distribution.

The principal cost of stratification is that if it does not match patterns in the target species' density, the variance of the abundance estimate may be higher than in an unstratified design, perhaps considerably so. This would be likely only if effort levels within strata were in the wrong rank order of true density, which could be avoided by conducting a pilot study first.

Pilot surveys can provide valuable guidance on survey design. The practical constraints on a survey in that habitat will become clear, and the pilot survey could generate sufficient density data to facilitate good stratification of effort in the main survey. The person who is going to analyse the data from the main survey should be involved in the pilot survey at least, so that s/he understands the constraints on data collection, and has input into designing the main survey.

A useful way to retain flexibility in stratification, and to avoid the possibility of poor stratification, is to use lines at spacings that can be evenly divided. An example would be a stratification scheme that has parallel lines at $4 \mathrm{n}$ mile intervals at the lowest level of survey effort, lines at $2 \mathrm{n}$ mile intervals at the middle level of effort, and for the most intensive level has lines at $1 \mathrm{n}$ mile (e.g. Jefferson, 2000; Slooten et al., 2006). In this scheme, if an area with a low level of effort produces an unexpectedly high number of sightings, inserting the intervening lines could be done to bring the effort up to the next stratification level. Such increases in effort must cover the entire stratum and strata must be designated prior to the 
survey. This is, in effect, a two-phase sampling scheme. The first phase of sampling is used to decide the intensity of the second phase.

A further development is adaptive sampling, in which a base level of effort is applied, and more effort added, e.g. by starting to zigzag, when encounter rates reach a trigger value (Pollard, Palka \& Buckland, 2002: Pollard, Buckland \& Borchers, 2004). Such designs can produce gains in precision, but are potentially biased (Francis, 1984). A key factor is the amount of extra effort added in the adaptive phase (Francis pers. comm.). For example, if most of the total effort is at the base level, bias will probably be small. As this level decreases, at some point the level of information on density will become insufficient for good 'decisions' on when to start adding more effort. Whether and when the trigger level will be reached become increasingly dependent on chance. Such surveys also need a trigger level for resuming the base level of effort. Adaptive surveys are most practical when there is a relatively high density in some areas and high variance in density. They are difficult to optimize in multispecies surveys (Thomas et al., 2007). Palka \& Pollard (1999) conducted an aerial survey in which they compared standard and adaptive approaches; the adaptive approach did result in more sightings but only gave a slight improvement in precision. In the context of most cetacean surveys, we believe that a simpler approach is preferred.

In data analysis, it is possible to post-stratify data by factors that affect the probability of seeing distant groups. Such factors include group size, sea state and (for aerial surveys) cloud cover. Line-transect analysis methods are typically robust to pooling data from different conditions, so it may not be necessary to stratify by such factors when estimating effective strip width (Buckland et al., 2001). Methods are available within the program Distance to adjust for situations when larger groups have a greater probability of being seen at distance than smaller groups. Post-stratification is, however, desirable if the probability of detecting animals on the transect line $[\mathrm{g}(0)]$ is found to vary with survey conditions or group size. This is especially important if different geographical strata have different sighting conditions but are (because of small sample size) pooled for estimating Effective Strip Width (ESW). For these reasons, factors that affect sighting conditions should be recorded frequently throughout a survey. A new development in the field is multiple covariate distance sampling, in which the effects of covariates of sighting conditions (such as group size, Beaufort state or sighting platform) are explicitly modelled as part of the detection function. This advanced analysis technique is available in program Distance 5.0 and a description of the technique can be found in Buckland et al. (2004). One advantage of this technique is that it avoids the potential problem of stratifying data into bins with inadequate sample sizes. An example applied to fin whale Balaenoptera physalus, humpback and minke whale B. acutorostrata can be found in Zerbini, Waite \& Wade (2006).

\section{Adding extra lines to estimate ESW robustly}

Estimating effective strip width is a process of fitting models to observed sighting distances. Usually, the fit (and hence the variance associated with ESW) will improve with more data. Buckland et al. (2001) recommend that 60-80 sightings are usually required to achieve a good fit and that 20-30 sightings should be considered a minimum. If there are sufficient existing data on density, it is sometimes possible to design a survey so that this number of sightings will be achieved. In low-density areas, however, unrealistic effort levels might be required to reach this target. In that case, a good solution is to run extra lines in an area with higher densities but the same sighting conditions (and same boat or aircraft and observers), and use these sightings to improve estimation of ESW (e.g. Dawson et al., 2004; Slooten et al., 2006). If the extra sightings are allocated within the study area, that area should be post-stratified so 
that extra sightings contribute not only to improving estimation of ESW, but also to estimation of group size and encounter rate within that stratum. If the extra lines are allocated outside the study area, the sightings can be used only to improve estimation of ESW.

\section{SURVEY MODE - PASSING OR CLOSING?}

Two modes are commonly used for cetacean line-transect surveys. In passing mode, the survey vessel continues to travel along the established transect line after a group of marine mammals is seen. Group size and species composition are estimated from the transect line while survey effort continues. In closing mode, the vessel leaves the transect line when a sighting is made and approaches ('closes on') the group of animals in order to estimate group size and species composition. Additional sampling can occur on closing mode surveys, including photoidentification and genetic sampling. In closing mode, the vessel can either resume survey effort by returning to the transect line at the same point it left that line, or resume survey effort immediately after all data are collected from a given group. The former approach is preferred to minimize potential biases (see below).

Closing mode has a potential for generating biased estimates of group density by a variety of different mechanisms. If effort is resumed without returning to the track line, the survey vessel may be drawn into areas with higher density, thus resulting in abundance estimates being biased high. If the vessel does return to the track line and the same group is re-sighted and is inadvertently recorded as a new sighting, abundance will again be overestimated. Conversely, if the survey is designed to fill a certain amount of time (e.g. 20 days of ship time) rather than a given number of transect lines, closing mode can act to underestimate abundance because time spent in closing mode cannot be spent running lines and making new sightings. Hence, the vessel spends a smaller fraction of each survey day searching for cetaceans in high-density areas, and therefore, such areas may be underestimated in the overall survey. The biases associated with closing mode can be minimized by (i) keeping track of the previously sighted group while returning to the transect line in order to guard against double counting; and (ii) preventing the vessel from being drawn into high-density areas by setting limits on the distance from the transect line that the survey vessel can stray.

Passing mode also has potential for generating biased estimates of group size and incorrect species determinations. Often, group size of cetaceans can only be estimated accurately if the observer is in close proximity to the group and is underestimated at greater distances. For example, in one survey post-encounter estimates of group size of 'transient' killer whales were $26 \%$ higher than initial group size estimates (Zerbini et al., 2007). Also, identifying species can be very difficult at distances of more than a few hundred metres. For multi-species groups of cetaceans, species composition may be even more difficult to estimate than group size and may require several passes in close proximity to the group. Species identification and group size estimation in passing mode can often be improved by using higher-power binoculars than are normally used to search for groups. If species identification at distance is difficult and samples sizes are sufficient, it is reasonable to truncate the perpendicular distance data to eliminate most or all sightings that cannot be identified to species.

Clearly, there is no perfect survey mode for cetaceans. The choice between passing mode and closing mode typically depends on whether group size and species can be accurately determined from the transect line. This is often a judgement call, but experiments can be done during a pilot survey wherein observers are required to make group size estimates and species determinations from the transect line and then are asked to update their estimates after the group is approached. If species composition and group size cannot be accurately determined from the transect line, closing mode is recommended. Every effort should be made to reduce 
the potential biases associated with closing mode (see above). For surveys in which group sizes are relatively small and easily determined, multiple groups can be in sight simultaneously, and if it is difficult to track individuals from one surfacing series to the next, passing mode is recommended. As examples, passing mode has been used for harbour porpoises Phocoena phocoena and minke whales, two species which occur in small groups and which are difficult to track from one surfacing series to the next if multiple groups are in the same area.

\section{FIELD METHODS AND PROTOCOLS}

From an observer's point of view, the key assumptions of distance sampling are that: (i) the probability of detecting an animal of interest on the track line $[\mathrm{g}(0)]$ is one (or can be estimated); (ii) the animals of interest do not move in response to the survey platform before detection (or the extent to which they do can be estimated); (iii) the species are identified correctly; and (iv) the distance to the sightings is accurately estimated, as is (v) group size. Meeting these assumptions requires substantial skill on the observer's part. Additionally, good observers have long attention spans, can tolerate long periods of discomfort and are not prone to motion sickness.

Training of observers is extremely important. If possible, we recommend training in an area with a high density of the target species and running transects there until each observer has reached a minimum number of sightings (e.g. 20), and is totally familiar with scanning and recording procedures (e.g. Dawson et al., 2004). These data are not used in the subsequent abundance analysis. For very rare target species, training on other species that provide similar sighting cues may be appropriate. This training period is also very important for the aircraft pilot or boat captain. Navigating transect lines precisely is a skilled task, and a poorly trained pilot or captain can cause unnecessary delays and increase the cost of a survey. Familiarity with the GPS system to be used is very important.

To address the first two assumptions above, it is important that observers scan as far ahead of the vessel as they reasonably can. In this way, an animal on the track line has more time to be detected, and has the greatest chance of being detected before it reacts to the survey vessel. For these reasons, as well as being able to measure angles to sightings, using binoculars is strongly encouraged. Scanning behaviour, i.e. how much time observers should spend looking in different sectors, should be concentrated near the track line, and this should be discussed and practised. For example, if one observer is used on each side, each should probably spend about twice as much time scanning from dead ahead to $45^{\circ}$ than from $45^{\circ}$ to $90^{\circ}$. Additionally, it is good practice for two observers to overlap their scans on the track line. Observers often feel a temptation to try to make sightings as far away to the side of the survey platform as they can, and are often competitive. This should be strongly discouraged, as it potentially violates assumptions 1 and 2 above, and creates a distribution of sightings that is difficult to model for the purposes of fitting the detection function. On the other hand, if observers focus too closely on the track line (e.g. $10^{\circ}$ either side of the track line), this can create too narrow a 'shoulder' in the distance data, and make estimation of the detection function unreliable. To maximize consistency, it is helpful to write a brief observer manual, and ask observers to reread it regularly throughout the survey.

Correct species identification is obviously important, as is accurate estimation of group size. Both should be addressed in the training period. Assessing group size is often less of a problem on coastal and riverine surveys than it is on oceanic surveys, because coastal and riverine species typically have much smaller group sizes. If observers are not confident about the size of a particular group, breaking off the transect to approach the group (closing mode) can be used to improve estimation. 


\section{MEASURING DISTANCES TO SIGHTINGS}

Line-transect surveys require data on the perpendicular distances of sightings to the track line. In surveys using binoculars, the vertical angle is usually measured by counting the number of reticle divisions from the horizon down to the sighting (Lerczak \& Hobbs, 1998). In coastal surveys, the horizon is often obscured by land. In this case, the observer measures the declination from the shoreline to the sighting (using binocular reticles) while the vessel's captain simultaneously measures the distance to the shoreline in the same direction via RADAR (a laser-range finder can also be used if close to shore). In analysis, you can add the expected declination (in reticles) from the horizon to the shoreline given its distance to your observed declination, and then convert this total declination to a true distance to the animals (e.g. Barlow, 1995; Lerczak \& Hobbs, 1998). Distance to land can also be measured from the boat position (if that is known accurately, e.g. via GPS) using accurate paper or digital charts. Even inexpensive, hand-held GPS units are accurate enough for this purpose without differential correction (e.g. Garmin eTrex; over 48 hours $50 \%$ of fixes were $<3.8 \mathrm{~m}$ of the true position, and 95\% were $<6.7 \mathrm{~m}$; Wilson, 2007).

Distances to sightings can also be measured photogrammetrically (Leaper \& Gordon, 2001). A video camera is used to gain images which show the object of interest, and the horizon simultaneously. Provided that camera height and lens focal length are known, these images provide measurements of sighting distance via the same trigonometry used to calculate vertical angles from binocular reticles. When used from a large survey vessel, Williams et al. (2007) found this method to be unbiased and more reliable than measurement via reticles. For both of these measurement methods, accuracy increases with increasing platform height.

The 25-power binoculars used on some shipboard surveys allow sightings to be made at great distances (e.g. Wade \& Gerrodette, 1993), but are large, require pedestal mounting, and their utility is compromised by vessel movement and vibration. Hence, they are seldom useful on vessels smaller than $c .30 \mathrm{~m}$ (smaller in calm conditions). Hand-held (typically 7-power) binoculars offer a practical alternative for smaller survey vessels. Several brands offer reticule scales that allow measurement of vertical angles (Kinzey \& Gerrodette, 2001), along with built-in compasses to measure horizontal angles (by taking the compass bearing to the sighting, and another of the vessel's course). Compasses are susceptible to deviation caused by magnetic fields or ferrous metals, and may be unusable on steel vessels. If deviation is not excessive, each binocular should be assigned to a particular observer position, and a deviation card made for that binocular/position combination. Our experience, and that of Jefferson (2000), is that such binoculars work better than angle boards (see below). It should be noted that in-built compasses intended for use in the Northern Hemisphere may not be accurate in the Southern Hemisphere (and vice versa) as the 'dip' of the card will be wrong, and may prevent it from moving freely.

Horizontal angles can also be estimated using an angle board, which resembles a large protractor equipped with a pointer at its centre (Buckland et al., 2001). The observer aligns the pointer with the sighting, and then reads off the angle on the board. In our experience, observers using angle boards are more prone to 'rounding' their sighting angles (e.g. record a sighting at $3^{\circ}$ as either $0^{\circ}$ or $5^{\circ}$ ) than those using binocular compasses. To avoid this, the correct procedure is to line up the pointer first, without looking at the angle scale, and then read the corresponding measurement.

In closing mode surveys, GPS can be used to measure distances directly, by recording a fix when the animals are first seen, then again when the animals are reached (Dolar et al., 2006). This approach will tend to overestimate ranges unless the target animals are stationary, and 
is not generally recommended. It is probably most appropriate in surveys from small boats where the 'closing' can be done at reasonably high speed in order to limit the effect of animal movement.

Laser rangefinders are now readily available, relatively inexpensive (e.g. US\$200-400), and highly accurate (typically $\pm 1 \mathrm{~m}$ ). However, except in the case of large targets (i.e. whales) at close range $(<200 \mathrm{~m})$, they seldom receive enough reflected energy to measure distances to sightings. They are, however, extremely useful for measuring distances to land where land is close $(<1 \mathrm{~km})$, and for practice in estimating distances.

If the survey vessel is too small to have a raised platform, observers will probably not be able to estimate distances via reticle-equipped binoculars, and may have to estimate distances by eye. With training, observers can make reasonably accurate judgements of sighting distance (e.g. Dolar et al., 2006; Williams et al., 2007), and some surveys use estimations 'by eye' for at least some (or all) of their distance data (e.g. Hammond et al., 2002). Observers differ in their ability to estimate distances, and so must be calibrated (in this process a laser range finder is very useful; Smith et al., 2004). Additionally, because each observer's ability may drift with time, training must be ongoing throughout the survey. Observers must consciously avoid rounding their estimates to convenient values. Even with thorough training, the accuracy of estimates done 'by eye' will always be open to question. Since accuracy of sighting distances is a key assumption in distance sampling, it is always better to measure rather than 'guesstimate' distances.

Whatever methods are used to estimate distances to sightings, we recommend daily inspection of the data in order to detect problems which can make fitting a detection function much more difficult. This is especially important during the training period and over the first few days of a survey. A histogram of distance data should have a 'broad shoulder' - the first few distance bins should be of reasonably similar height (Burnham, Anderson \& Laake, 1980). A spike in the first bin, caused by excessive focus on the track line, or rounding small angles to zero, is a particular problem (see Hiby \& Hammond, 1989; for several examples). Likewise, plotting the distribution of horizontal sighting angles can indicate whether observers are rounding angles to particular values (e.g. are there peaks at 5, 10, 20 degrees with few intermediate values?).

\section{Starting and stopping transect lines}

If the target species is most common close to the shore or riverbank, starting and finishing transects as close to that edge as possible is important to avoid bias. For navigational reasons, the vessel's captain might wish to turn early away from the shore near a transect's end, potentially lowering sighting rates. While vessel safety is the captain's responsibility, s/he should be encouraged to avoid doing this if possible. Also, when nearing the start of a transect line, we instruct observers to look away from the intended path until actually 'on effort'. The reason for this is that if observers have made a sighting while 'off effort' soon before a transect is begun, their attention might be diverted to this zone, and this can bias sighting rate.

\section{DATA RECORDING SYSTEMS FOR SMALL BOATS}

The accuracy and affordability of GPS navigation has made it indispensable in line-transect surveys. Virtually all GPS navigation units allow input of waypoints that allow precise and easy navigation of transect lines. Most units have NMEA output that can be routed to the serial port of a computer for storage and/or have in-built memory that can store the track 
surveyed ${ }^{2}$. Recording of track is important because actual track may be significantly longer than the straight-line distance between the start and end point, due to current, wind or course-keeping difficulty. Several free or inexpensive applications are available for downloading GPS track files ${ }^{3}$, and these can be extremely useful to provide a preliminary look at the survey track, and hence show whether course keeping was adequate, or lines were missed.

If the track is to be recorded on a computer, the same computer program might as well be used to record sightings. Most such programs record GPS position, date and time and prompt the user to input sighting information. At a minimum, this information includes sighting angles (vertical and horizontal angle in boat surveys), group size, species and sea conditions. Software developed to record data on line-transect surveys is freely available for both DOS and Windows operating systems (Table 1). A palmtop computer in a splash-proof housing, with a silicone membrane over the keyboard, is a practical solution on a small boat. Whatever recording system is used, it is important that the data can be recorded and corrected quickly and that a system is in place for recording simultaneous sightings. During a sighting, the recorder cannot observe. So, in areas where sightings are very frequent, it might be best to use a dedicated recorder. An even less complex recording system might comprise only a GPS with internal track recording, and a dictaphone for each observer. Each dictated sighting must record the exact time (synchronized to the GPS).

\section{DATA RECORDING SYSTEMS FOR AIRCRAFT}

GPS is, if anything, even more important on aerial surveys. We have been surprised to find that commercially qualified pilots are often not trained in GPS use, and need training and practice in order to navigate the lines properly. If using a new pilot, we sometimes send him/her our GPS unit before we arrive for a survey, and usually spend the first flight practising transect starts in addition to training observers. We have found that 'moving map' GPS plotters are easier for most pilots to use.

Because of the speed of the aircraft, data from sightings must be recorded instantly. There may be no time for a recorder to enter sightings s/he has been relayed by observers (there is often no space for a dedicated recorder either). A simple data-recording system has a central GPS which is used by the pilot and which feeds NMEA data to a computer. This computer logs the aircraft's track, and is used to record which transect is being flown, weather conditions, and start and stop points. Each observer is equipped with a dictaphone, inclinometer and a digital clock. At the start of each flight, the clocks are synchronized to the GPS, and velcroed near the bottom of each observer's window - ideally so s/he can see a clock without looking away from the sighting. On making a sighting, the observer starts his/her dictaphone, and dictates the sighting data, along with the precise time (to the second) that the sighting passes abeam. On returning from a flight, each observer transcribes their own dictaphone tape into a spreadsheet. Via later comparison with the GPS tracking file, the sighting times are used to locate where each sighting was made. When there is space for a dedicated recorder, another technique that has been employed is to use software that can instantly store multiple sighting positions with a single keystroke for each sighting, and allows the filling in

\footnotetext{
${ }^{2}$ We have noted a several second error in the time stamps of the track recorded internally in some Garmin GPS units (e.g. Garmin GPS II+, 12XL). This error is constant and can be adjusted for, and arises from the time stamps not accounting for leap seconds (T. Thomas, pers. comm). In boat surveys, this error will probably be inconsequential, but it can be important in aerial surveys. The error is not present in the NMEA data sent from the GPS unit's serial port.

${ }^{3}$ Examples are: DOS, mac, unix, http://www.gpsbabel.orgGPSBabel; Windows, http://www.gpstm.com; Mac, http://www.macgpspro.com/.
} 
of details directly afterwards. Observers can communicate their sighting information to the recorder over voice-activated headsets, while the recorder is still able to log the position of any new sighting detected in the meantime.

It is important that observers conducting independent observer studies do not communicate with each other while on effort but can still receive instructions from the survey leader. Noise within the aircraft, and the fact that observers are jammed against their windows, usually prevents an observer noticing when another has a sighting. We have found that dictaphones work surprisingly well despite the noisy environment.

Various other recording systems have been developed. Some use a central multi-track recording device, such as a hard-disk recorder. The advantage of a multi-track recorder is that the individual records are precisely synchronized in time which aids in the detection of duplicate sightings when observers are working independently. Given the expense of obtaining survey data, a redundant system should be considered as insurance against lost data.

\section{ESTIMATING THE FRACTION MISSED ON THE TRACK LINE}

No cetacean survey can reasonably expect to see all the animals present within the area surveyed. Line-transect methods, when properly applied, appropriately correct for animals missed as a function of their distance from the track line. As previously mentioned, though, one key assumption of line-transect methods is that the probability of detection on the track line is certain [i.e. $\mathrm{g}(0)=1.0$ ]. This assumption will often be violated. For example, some animals will probably be underwater and not available for counting ('availability bias'; sensu Marsh \& Sinclair, 1989). Also, for a variety of reasons including glare, fatigue and momentary inattention, no observer will see all of the dolphins that are available at the surface ('perception bias'; sensu Marsh \& Sinclair, 1989). In some cases, the combined effect of these, often termed the 'fraction missed' on the track line, is very large. For surveys of absolute abundance, estimating the fraction missed is vital.

For cetaceans, the potential bias from availability bias is a function of dive time and the relative speed of the survey platform. For aerial surveys, because of their speed over the water, the proportion of time that the target species spends at the surface is important for all species. Hence, aerial surveys using single aircraft need additional data to assess availability bias. On boat or ship surveys, availability bias is potentially the largest problem for longdiving species that spend little time at the surface; these species generally occur in deep water and will likely not be the target of inshore surveys. For very long divers, it may be necessary to model diving behaviour to adequately estimate availability bias (e.g. Barlow, 1999). For boat surveys of small cetaceans, typical vessel speeds are slow enough to ensure that small cetaceans surface within visual range at least once before the survey vessel passes; hence, a track line detection probability of less than 1.0 would be largely caused by perception bias. Perception bias is potentially largest for species that occur as single animals or in small groups and do not show much of their body when surfacing, such as harbour porpoise and minke whale. Estimates of perception bias have usually been $>0.9$ for dolphins that occur in large schools, for whales with large blows, and for larger delphinids that occur in groups and have relatively large dorsal fins (e.g. killer whale) (e.g. Barlow \& Forney, 2007).

Perception bias can be estimated using two independent teams of observers who can (post hoc) determine whether they detected the same groups of animals or not. The observer teams can be on the same platform, but need to be arranged so they do not give clues to each other about groups that have been detected. Alternatively, the two teams can be on separate platforms surveying simultaneously. A combination of perception and availability bias can be estimated through tracking methods, where an individual group of cetaceans is tracked by 
one observer or team and it is determined whether the sighting team detects that group or not. The tracking team can be on a separate platform, such as a helicopter (e.g. Buckland \& Turnock, 1992), on land (e.g. Laake et al., 1997) or even on the same platform. The key to estimating $\mathrm{g}(0)$ where availability bias is accounted for lies in having a separation in time between when a group begins to be tracked, and when the observer team has a chance to detect them. If the tracker is on the same platform, s/he have to be able to look well ahead of the observer team. For example, in some cetacean surveys, this has been accomplished by having a tracker using $25 \mathrm{x}$ binoculars to look only for sightings well ahead of the ship (Hammond et al., 2002). This can also be done having a tracker using 25x binoculars in combination with an observer team using $7 \mathrm{x}$ binoculars.

Platform choice (boat or aircraft) may restrict methods available for bias assessment. Two independent teams of observers, on separate observation platforms but on the same vessel, have been used to quantify perception bias (as well as correct for reactive movement; see below) for harbour porpoise (Palka, 1995). Dual, independent, observer teams, however, are not likely to be practical on vessels less than, $20 \mathrm{~m}$ long. An independent observer looking through a belly window was used to assess perception bias on an aerial survey for multiple species of cetaceans (Forney et al., 1995). Sightings made by two independent teams of observers have been used to quantify perception bias in aerial surveys of dugongs (Marsh \& Sinclair, 1989) and Hector's dolphins (Slooten et al., 2004). Availability bias has been estimated in an aerial survey of dugongs using helicopter observations of dugong Dugong dugon models at various depths, and data from animals tagged with time-depth recorders (TDR) (Pollock et al., 2006). TDR data alone cannot answer the key question, i.e. what proportion of the time is the target species visible from the survey height? If one assumes that the animal is only visible when the tag is at the surface, this will underestimate the proportion of time the animal is visible from the air, and therefore overestimate abundance.

Tandem aerial surveys (the dual-platform approach), using two observer teams in independent aircraft, were used to estimate the fraction missed during surveys for bottlenose dolphins Tursiops truncatus off the Californian coast (Carretta, Forney \& Laake, 1998) and for harbour porpoise in the North Sea (Borchers et al., 1998). This sophisticated approach is probably beyond the resources of most research teams. Barlow et al. (1988) used shore and helicopter observations to estimate what proportion of the time harbour porpoise were visible near the surface, and hence available to be counted.

For small cetaceans found very close to shore, it is possible to estimate $g(0)$ via repeated trials in which a theodolite is used on shore to track nearby groups, while a survey comes through the area. Laake et al. (1997) used this approach for an aerial survey of harbour porpoise, but the method could likely be applied to a vessel survey as well. Provided suitable observation points are available, this approach is much more affordable than using a helicopter. Such trials would have to be done over many days to dilute any effect of the same cetaceans being repeatedly exposed to the survey vessel. The crucial assumption would be that $\mathrm{g}(0)$ measured in such locations was representative of the rest of the survey area. This same approach could equally well be used to measure the effect of reactive movement.

In some habitats, availability bias can vary geographically. For example, small-scale differences in turbidy affect the sightability of submerged dugongs (Pollock et al., 2006). Ways to mitigate this problem include: (i) stratifying sampling for availability bias over the range of conditions experienced in the actual survey; (ii) recording water colour as a proxy for turbidity, and using it as a covariate in analyses; and (iii) recording whether sightings are made at or under the surface and examine the ratio of these two types of sightings across different habitats for evidence of bias. 
With good, well-trained observers on an appropriate platform, 'perception bias' will be small for most species. Nevertheless, ideally each survey should attempt to empirically estimate it. The topic of estimating $\mathrm{g}(0)$ is covered elsewhere in more detail (e.g. Buckland \& Turnock, 1992; Palka, 1995; Barlow, 1999; Palka \& Hammond, 2001; Buckland et al., 2004).

\section{THE EFFECT OF REACTIVE MOVEMENT}

Responsive movement by the target species either towards or away from the survey platform will bias abundance estimates positively or negatively, respectively, and often occurs on cetacean surveys. The effect of reactive movement may be particularly important in coastal surveys from small boats. Because sightings are typically made at closer ranges, the animals sighted are more likely to have reacted to the survey vessel. Observed densities may be artificially lowered by avoidance (e.g. harbour porpoise, Palka \& Hammond, 2001) or raised by attraction (Dall's porpoise Phocoenides dalli, Turnock, Buckland \& Boucher, 1995; Hector's dolphins, Dawson et al., 2004). From a conservation perspective, the latter is worse, because it could result in impacts being judged as sustainable when they are not. At a minimum, observers should collect data on the orientation of animals when they are first seen. If disproportionately many were heading towards the boat when first seen, this could be evidence of attraction.

The effect of reactive movement on abundance estimates can be minimized by using higher sighting platforms and/or binoculars to detect animals at greater distances, before they react to the vessel. This may require limiting survey conditions to those which allow animals to be seen before they react. For example, Barlow (1995) showed that very few Dall's porpoises were approaching the vessel when first seen if they were seen in calm seas, so he estimated their abundance only from data collected in Beaufort sea states of two or less. Alternatively, the effect of reactive movement can be quantitatively assessed. Often, this has involved a two-platform approach (e.g. Palka, 1995) in which the topmost team looks far ahead. In general, dual platform tracking methods (described above for correcting for availability bias) can be used to correct simultaneously for both availability bias and responsive movement. For example, Buckland \& Turnock (1992) proposed methodology using a helicopter combined with a ship survey to correct for both biases for Dall's porpoise. Any approach can work if sightings can be made far enough ahead to justify the assumption that the animals have not yet responded to the survey vessel before being seen by the observer team. It is obviously better if the second team of observers is not on the boat that the animals are responding to.

Boat/helicopter studies are an excellent way to accomplish this. Helicopters are expensive, but this cost can be minimized by conducting the studies in an area where sightings are very frequent. It is also worthwhile remembering that only one observer is needed in the helicopter (see Hector's dolphin case study below), so small, relatively inexpensive, two-person helicopters can be used. Also, using an expensive tool for a short time can be cheaper than using a less expensive tool for longer. Some surveys have managed to get helicopter time supplied by the military [e.g. Jefferson et al. (2002)]. As above, if the species of interest is found very close to shore, simultaneous boat survey/cliff-top observations could be used to quantify reactive movement.

\section{CASE STUDIES}

\section{Example 1: Hector's dolphin survey around Banks Peninsula}

Dawson et al. (2004) carried out a line-transect survey of Hector's dolphin abundance in New Zealand waters. They chose to use a catamaran for reasons of cost and practicality. Hector's 
dolphins are found very close to shore, and sometimes occur in very shallow water, making it impractical to use a large vessel. In addition, chartering a large research vessel was well beyond the available research funding, which came from levies imposed on gill-net fisheries with demonstrated dolphin by-catch.

Having decided on a relatively small vessel, a catamaran was chosen for its greater lateral stability. The vessel used for this particular survey was the 15-m sailing catamaran Catalyst, which could cruise under power at 10 knots $(18.5 \mathrm{~km} / \mathrm{h})$. A collapsible observation platform was built, giving three crew (two observers and one recorder) an eye height of about $6 \mathrm{~m}$, which was sufficient to use binoculars with reticles to estimate the distance to each sighting. Non-ferrous construction of the platfom and vessel allowed compasses in the binoculars to be used to estimate the horizontal angle to each sighting.

Transect lines were placed at a $45^{\circ}$ angle to the shoreline to ensure the survey sampled across alongshore and offshore gradients in dolphin density. The primary area surveyed was from the coast out to $4 \mathrm{n}$ mile offshore. Peninsulas and bays were challenges for survey design. Along relatively straight sections of coastline, all that was needed was to start with a random starting point and plot lines at a constant distance (e.g. 2 nautical miles) apart. On curved coasts, the survey area was divided into blocks, and lines placed at $45^{\circ}$ to the coastline within each block (Fig. 4). Long harbours (e.g. Akaroa and Lyttelton harbours, Flea Bay) were surveyed according to the scheme shown in Fig. 3a, using transects spaced 1 nautical mile apart. Because sighting conditions differed systematically between the open coast and harbours (inlets), separate detection functions were computed for each habitat type. In harbours, sets of transect lines as shown in Fig. 3a, each with different randomized start points, were replicated until the target of 60-80 sightings was achieved. On the open coast, this target number of sightings was achieved without replicate sets of lines.

A major challenge was that Hector's dolphins are strongly attracted to survey vessels, which has the effect of increasing the apparent density. On the first survey, we noted the direction dolphins were facing or travelling when first sighted. Analysis of these data showed that a far greater proportion than expected by chance were facing in the direction of the survey vessel. On the second survey, we therefore used a relatively inexpensive two-person helicopter (Robinson R22) which was flown in front of the survey vessel. Sightings made by one observer in the helicopter were compared with sightings made by the observers on the vessel to estimate the proportion of dolphin groups that were missed, and to determine whether the dolphins had moved towards the vessel before they were detected by the observers (Buckland \& Turnock, 1992; Dawson et al., 2004).

The vessel's RADAR was used to measure the helicopter's position while it briefly hovered over a sighting. The observer on the helicopter communicated with a crew member in the wheelhouse of the vessel, but not with the crew on the observation platform. The flying height of the helicopter (500 feet) made it impossible for the observers to see the helicopter while they were using their binoculars. They could, of course, hear the helicopter and see it with the naked eye. The observers were strongly encouraged to ignore the helicopter and to stick to their normal scanning and sighting routine. Further, the helicopter pilot was instructed to sometimes behave as if on a sighting when not, further encouraging the observers to ignore the helicopter.

The joint boat-helicopter surveys described above resulted in a correction factor of 0.5 . In other words, without correction for attraction to the survey vessel, the above surveys would have overestimated abundance by a factor of 2 . 


\section{Example 2: Amazon River dolphin survey}

Riverine habitats pose some of the greatest challenges for cetacean surveys. However, many river dolphin and porpoise populations are endangered, and there is a lack of abundance information for most. Some of the challenges include:

1. Complicated topography - river channels are long, narrow and often convoluted. River levels may vary by tens of meters between wet and dry seasons and may flood adjacent forests for much of the year. Many parts of the river system may not be navigable by large vessels due to shifting sand bars.

2. Currents - river currents are relatively fast compared with most ocean currents, and they vary throughout the river. Typically, currents are faster in the centre of rivers and are slow at the margins. Consequently, in order to navigate a zigzag transect across a river, the course heading needs to vary with the current speed. Eddies, particularly at the confluence of rivers or downstream from islands add complexity to the habitat. Currents can cause a patchwork of ripples or standing waves which can make cetaceans harder to see but which cannot easily be quantified as a covariate in line-transect analyses.

3. Navigation - most riverboat pilots navigate by visual landmarks. They are typically unfamiliar with GPS or with navigation by compass. They have no experience navigating a straight course to follow defined transect lines. Nonetheless, local knowledge is essential in navigating most rivers. Upriver navigation may be necessarily slower than downriver navigation due to the effects of currents.

4. Animal distribution - river dolphins are not distributed uniformly in their environment. Some species appear to be most abundant along the banks and others favour the centre of large channels. Survey vessels are constrained by the navigable depth of the river, thus given the non-uniform distribution of the animals, it may not be possible to meet the line-transect assumption that animals are uniformly distributed with respect to the distance from the survey vessel (within the search distance).

In 1993, Omar Vidal and colleagues organized one of the first line-transect surveys for river dolphins. The survey estimated the abundance of the Amazon River dolphin Inia geoffrensis and tucuxi Sotalia fluviatilis in a section of the Amazon River bordering Columbia and Peru (Vidal et al., 1997). They used a local 17.5-m riverboat with a one-cylinder diesel engine, and they built an observation platform on the top of the wheelhouse (Fig. 1). Due to currents and direction of travel, vessel speed varied between 5 and $15 \mathrm{~km} / \mathrm{h}$. The survey was conducted in the low-water season when the dolphins are concentrated in the channels and are not in the flooded forests.

From prior work, they knew that the density of dolphins was much higher near the riverbanks, around islands and in the small tributaries and lakes associated with the Amazon. For this reason, they designed a stratified survey, with more intensive survey efforts in the areas of higher expected density. However, because the near-bank regions and the small tributaries were so narrow and because dolphins are not uniformly distributed with respect to distance from the bank ${ }^{4}$, a line-transect survey design was deemed impractical for these areas. Their compromise design included strip transects along the banks and around the islands in the main channels and in the smaller channels $(<200-\mathrm{m}$ width) and included zigzag linetransects in the centre of the large channels ( $>300 \mathrm{~m}$ but typically over $1 \mathrm{~km}$ in width; Fig. 5). In the main channels, the strip transects were conducted at a distance of $100 \mathrm{~m}$ from the riverbanks and included $100 \mathrm{~m}$ on each side of the vessel. This strip width was defined to be

${ }^{4}$ One of the line-transect assumptions is that animals are uniformly distributed with respect to distance from the survey vessel. 


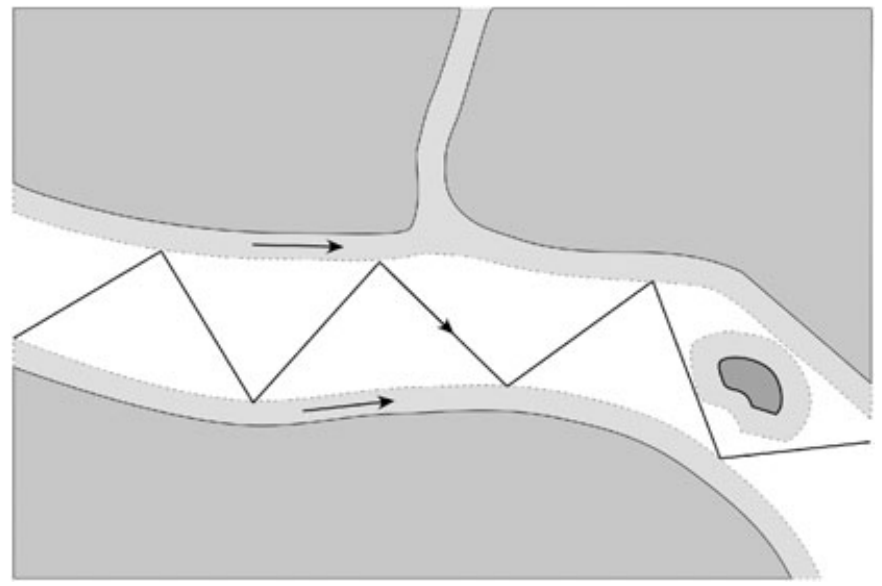

Fig. 5. Schematic representation of the survey design used in the Amazon river. A 17.5-m river boat surveyed the zigzags using line-transect methods, while a small outboard-powered open boat surveyed the light shaded area using strip-transect methods. For practicality, the zigzags followed the course of the river, rather than being drawn to a bounding box outside it (see Fig. 3); hence, this is not an ideal equal-coverage design.

conservatively narrow to increase the likelihood that the strip transect assumption (that all animals are seen within the defined strip) would be met; analysis of the line-transect data justified this by showing that the detection probability was relatively flat out to $200 \mathrm{~m}$ on each side of the ship (Vidal et al., 1997). The line-transect densities of Inia and Sotalia in the centre of the large channels were 0.57 and 0.89 dolphins $/ \mathrm{km}^{2}$ (respectively) and the strip-transect densities along the main banks of the same channels were 2.02 and 2.78 dolphins $/ \mathrm{km}^{2}$ (respectively). Given this three- to fourfold difference density in the two habitats for both species, the precision of the survey undoubtedly benefited from the stratified survey design.

Analysis of the above survey required more data than is typically recorded during ship surveys at sea. During the survey, the width of the channels was recorded frequently and proved to be essential in the analysis. An optical rangefinder was used to measure distance to the riverbank up to approximately $1 \mathrm{~km}$. Because the animals were only visible for a few seconds and because the optical rangefinder did not work on the ripple left behind after a surfacing, distances to dolphins were estimated by eye ${ }^{5}$. Given the uncertainty in using distances estimated by eye, observers were frequently calibrated during the survey by asking them to estimate the distance to a floating object (typically a clump of reed grass). Estimates from each observer were recorded and they were then told the distance measured via an optical rangefinder. Data from the distance calibrations showed that observers can be trained to make unbiased estimates of distance by eye out to a distance of approximately $450 \mathrm{~m}$ (Anonymous, 1993). Unlike most strip transects, perpendicular sighting distances were recorded for all sightings to allow for post hoc adjustment of the strip width if necessary. Water turbulence was recorded as a categorical variable to account for the effect of river currents on the observers' ability to see dolphins.

In general, all aspects of the survey worked well as described above. The major shortfall of the Amazon survey was that no attempt was made to estimate fraction of animals missed by

\footnotetext{
${ }^{5}$ Reticules in binoculars could not be used because the horizon was obscured by trees and the ship did not have
} a radar to estimate the actual distance to the bank. 
the observers $[\mathrm{g}(0)]$. Vidal et al. (1997) suggested the use of one or more rear-looking observers to act as quasi-independent sighting platform.

\section{CONCLUDING REMARKS}

In summary, line-transect survey methods provide a well-understood and powerful set of tools to gain robust estimates of abundance, which are often a precursor for conservation action. In several cases, the methods have been adapted to work well from small boats, making them much more affordable and hence more suitable for developing countries. Irrespective of whether a boat or aerial survey platform is chosen, adherence to relatively straightforward design principles will dramatically increase the robustness of results. Here we have tried to concisely and pragmatically summarize issues of design and methodology that relate directly to surveys of cetaceans in inshore and riverine waters. We have also tried to suggest less expensive options, when available, as we recognize that many of the inshore and riverine species of cetaceans that face substantial human threats occur in developing countries. As we have pointed out, platform choice (with no other resources available) may preclude some of the methods used for correcting for the fraction of sightings missed on the track line. If bias assessment is not feasible (we think it usually is), conducting properly designed surveys without such assessment is still much better than doing nothing. The resulting abundance estimates will usually be underestimates, but at least they will facilitate preliminary assessment of conservation status. Where quantitative abundance surveys cannot yet be conducted due to a lack of funds, important preliminary information can be obtained via interviews, land-based monitoring and carcass analysis (Aragones et al., 1997). These data may help design a robust abundance survey, but they should not be seen as an alternative to one.

\section{REFERENCES}

Anonymous (1993) Cruise Report of the M/S ALCARLETY: Amazon River Dolphins Survey, June, 1993. Available from Jay Barlow, NOAA Southwest Fisheries Science Center, 8604 La Jolla Shores Drive, La Jolla, CA 92037. USA.

Aragones, L.V., Jefferson, T.A. \& Marsh, H. (1997) Marine mammal survey techniques applicable in developing countries. Asian Marine Biology, 14, 15-39.

Barlow, J. (1988) Harbor porpoise, Phocoena phocoena, abundance estimation for California, Oregon, and Washington. I. Ship surveys. Fishery Bulletin, 86, 417-432.

Barlow, J. (1995) The abundance of cetaceans in California waters. Part 1: ship surveys in summer and fall of 1991. Fishery Bulletin, 93, 1-14.

Barlow, J. (1999) Trackline detection probability for long-diving whales. In: Marine Mammal Survey and Assessment Methods (Ed. by G.W. Garner, S.C. Amstrup, J. Laake, B.F.J. Manly, L.L. McDonald, \& D.G. Robertson), pp. 209-221. Balkema, Rotterdam, the Netherlands.

Barlow, J. \& Forney, K.A. (2007) Abundance and population density of cetaceans in the California Current ecosystem. Fishery Bulletin, 105, 509-526.

Barlow, J., Oliver, C.W., Jackson, T.D. \& Taylor, B.L. (1988) Harbour porpoise, Phocoena phocoena, abundance estimation for California, Oregon and Washington. II. Aerial surveys. Fishery Bulletin, 86, 433-444.

Borchers, D.L., Buckland, S.T., Goedhart, P.W., Clarke, E.D. \& Cumberworth, S.L. (1998) HorvitzThompson estimators for double-platform line transect surveys. Biometrics, 54, 1221-1237.

Buckland, S.T. \& Turnock, B.J. (1992) A robust line transect method. Biometrics, 48, 901-909.

Buckland, S.T., Anderson, D.R., Burnham, K.P. \& Laake, J.L. (1993) Distance Sampling: Estimating Abundance of Biological Populations. Chapman \& Hall, New York, USA.

Buckland, S.T., Anderson, D.R., Burnham, K.P., Laake, J.L., Borchers, D.L. \& Thomas, L. (2001) Introduction to Distance Sampling: Estimating Abundance of Biological Populations. Chapman \& Hall, New York, USA.

Buckland, S.T., Anderson, D.R., Burnham, K.P., Laake, J.L., Borchers, D.L. \& Thomas, L., eds. (2004) Advanced Distance Sampling. Oxford University Press, Oxford, UK.

Burnham, K.P., Anderson, D.R. \& Laake, J.L. (1980) Estimation of density from line transect sampling of biological populations. Wildlife Monograph, 72, 202. 
Calambokidis, J. \& Barlow, J. (2004) Abundance of blue and humpback whales in the eastern North Pacific estimated by capture-recapture and line-transect methods. Marine Mammal Science, 20, 63-85.

Carretta, J.V., Forney, K.A. \& Laake, J.L. (1998) Abundance of Southern California coastal bottlenose dolphins estimated from tandem aerial surveys. Marine Mammal Science, 14, 655-675.

Caughley, G. (1977) Analysis of Vertebrate Populations. John Wiley \& Sons, London, UK.

Dawson, S.M., Slooten, E., DuFresne, S.D., Wade, P.R. \& Clement, D.M. (2004) Small-boat surveys for coastal dolphins: line-transect surveys of Hector's dolphins (Cephalorhynchus hectori). Fishery Bulletin, 102, 441-451.

Dolar, M.L., Perrin, W.F., Taylor, B.L., Kooyman, G.L. \& Alava, M.R. (2006) Abundance and distributional ecology of cetaceans in the central Philippines. Journal of Cetacean Research and Management, 8, 93-111.

DuFresne, S., Fletcher, D. \& Dawson, S.M. (2006) Relative efficiency of line-transect survey designs for estimating abundance of inshore dolphins and porpoises. Journal of Cetacean Research and Management, 8, 79-85.

Forney, K.A., Hanan, D.A. \& Barlow, J. (1991) Detecting trends in harbor porpoise abundance from aerial surveys using analysis of covariance. Fishery Bulletin, 89, 367-377.

Forney, K.A., Barlow, J. \& Carretta, J.V. (1995) The abundance of cetaceans in California waters. Part II: aerial surveys in winter and spring of, 1991 and, 1992. Fishery Bulletin, 93, 15-26.

Francis, R.I.C.C. (1984) An adaptive strategy for stratified random trawl surveys. New Zealand Journal of Marine and Freshwater Research, 18, 59-71.

Gardner, S.C. \& Chávez-Rosales, S. (2000) Changes in the relative abundance and distribution of gray whales (Eschrichtius robustus) in Magdalena Bay, Mexico during an El Niño event. Marine Mammal Science, 16, $728-738$.

Gerrodette, T. (1987) A power analysis for detecting trends. Ecology, 68, 1364-1372.

Gómez de Segura, A., Hammond, P.S., Cañadas, A. \& Raga, J.A. (2007) Comparing cetacean abundance estimates derived from spatial models and design-based line transect methods. Marine Ecology Progress Series, 329, 289-299.

Gormley, A., Dawson, S.M., Slooten, E. \& Bräger, S. (2005) Mark-recapture estimates of Hector's dolphin abundance at Banks Peninsula, New Zealand. Marine Mammal Science, 21, 204-216.

Hammond, P.S., Mizroch, S.A. \& Donovan, G.P., eds. (1990) Individual recognition of cetaceans: use of photo-identification and other techniques to estimate population parameters. Report of the International Whaling Commission (Spec. Issue), 12, 440.

Hammond, P.S., Berggren, P., Benke, H., Borchers, D.L., Collet, A., Heide-Jørgensen, M.P., Heimlich, S., Hiby, A.R., Leopold, M.F. \& Øien, N. (2002) Abundance of harbour porpoise and other cetaceans in the North Sea and adjacent waters. Journal of Applied Ecology, 39, 361-376.

Hedley, S.L., Buckland, S.T. \& Borchers, D.L. (1999) Spatial modelling from line transect data. Journal of Cetacean Research \& Management, 1, 255-264.

Hiby, A.R. (1982) The effect of random whale movement on density estimates obtained from whale sighting surveys. Report of the International Whaling Commission, 32, 791-794.

Hiby, A.R. \& Hammond, P.S. (1989) Survey techniues for estimating abundance of cetaceans. Report of the International Whaling Commission (Spec. Issue), 11, 47-80.

Hobbs, R.C., Rugh, D.J. \& DeMaster, D.P. (2000) Abundance of belugas, Delphinapterus leucas, in Cook Inlet, Alaska, 1994-2000. Marine Fisheries Review, 62 (3), 37-45.

Holt, R.S., Gerrodette, T. \& Cologne, J.B. (1987) Research vessel survey design for monitoring dolphin abundance in the eastern tropical Pacific. Fishery Bulletin, 85, 433-446.

IWC (1994) Report of the International. Whaling Commission workshop and symposium on the mortality of cetaceans in passive fishing nets and traps. Report of the International Whaling Commission (Spec. Issue), 15,440 .

Jefferson, T.A. (2000) Population biology of the Indo-Pacific hump-backed dolphin in Hong Kong waters. Wildlife Monographs, 144, 65.

Jefferson, T.A. \& Hung, S.K. (2004) A review of the status of the Indo-Pacific Humpback Dolphin (Sousa chinensis) in Chinese Waters. Aquatic Mammals, 30, 149-158.

Jefferson, T.A., Hung, S.A., Law, L., Torey, M. \& Tregenza, N. (2002) Distribution and abundance of finless porpoises in Hong Kong and adjacent waters of China. Raffles Bulletin of ZoologySupplement, 10, 43-55.

Kinzey, D. \& Gerrodette, T. (2001) Conversion factors for binocular reticles. Marine Mammal Science, 17, $353-361$.

Laake, J.L., Calambokidis, J., Osmek, S.D. \& Rugh, D.J. (1997) Probability if detecting harbor porpoise from aerial surveys: estimating g(0). Journal of Wildlife Management, 61, 63-75.

Leaper, R. \& Gordon, J. (2001) Application of photogrammetric methods for locating and tracking cetacean movements at sea. Journal of Cetacean Research and Management, 3, 131-141. 
Lerczak, J.A. \& Hobbs, R.O. (1998) Calculating sighting distances from angular readings during shipboard aerial, and shore-based marine mammal surveys. Marine Mammal Science, 14, 590-599.

Marsh, H. \& Sinclair, D.F. (1989) Correcting for visibility bias in strip transect aerial surveys of aquatic fauna. Journal of Wildlife Management, 53, 1017-1024.

Muir, D.C., Koczanski, K., Rosenberg, B. \& Beland, P. (1996) Persistent organochlorines in beluga whales (Delphinapterus leucas) from the St Lawrence River estuary - II. Temporal trends, 1982-94. Environmental Pollution, 93, 235-245.

Palka, D. (1995) Abundance estimate of the Gulf of Maine Harbour Porpoise. Report of the International Whaling Commission (Spec. Issue), 16, 27-50.

Palka, D. \& Hammond, P. (2001) Accounting for responsive movement in line transect estimates of abundance. Canadian Journal of Fisheries and Aquatic Science, 58, 777-787.

Palka, D. \& Pollard, J. (1999) Adaptive line transect survey for harbor porpoises. In: Marine Mammal Survey and Assessment Methods (Ed. by G.W. Garner, S.C. Amstrup, J.L. Laake, B.J.F. Manly, L.L. McDonald \& D.G. Robertson), pp. 3-11. Balkema, Rotterdam, the Netherlands.

Pollard, J.H., Palka, D. \& Buckland, S.T. (2002) Adaptive Line Transect Sampling Biometrics, 58, 862-870.

Pollard, J.H., Buckland, S.T. \& Borchers, D.L. (2004) Adaptive distance sampling surveys. In: Advanced Distance Sampling (Ed. by S.T. Buckland, D.R. Anderson, K.P. Burnham, J.L. Laake, D.L. Borchers \& L. Thomas), pp. 229-259. Oxford University Press, London, UK.

Pollock, K.H., Marsh, H.D., Lawler, I.R. \& Alldredge, M.W. (2006) Estimating animal abundance in heterogeneous environments: an application to aerial surveys for dugongs. Journal of Wildlife Management, 70 , 255-262.

Seber, G.A.F. (1982) The Estimation of Animal Abundance and Related Parameters, 2nd edn. Charles Griffin and Co, London.

Slooten, E., Dawson, S.M. \& Rayment, W.J. (2004) Aerial surveys for coastal dolphins: abundance of Hector's dolphins off the South Island west coast, New Zealand. Marine Mammal Science, 20, 477-490.

Slooten, E., Dawson, S.M., Rayment, W.J. \& Childerhouse, S.J. (2006) A new abundance estimate for Maui's dolphin: what does it mean for managing this critically endangered species? Biological Conservation, 128, 576-581.

Smith, A.M. \& Smith, B.D. (1998) Review of status and threats to river cetaceans and recommendations for their conservation. Environmental Review, 6, 189-206.

Smith, B.D., Beasley, I., Buccat, M., Calderon, V., Evina, R., Lemmuel De Valle, J., Cadigal, A., Tura E. \& Vistacion, Z. (2004) Status, ecology and conservation of Irrawaddy dolphins (Orcaella brevirostris) in Malampaya Sound, Palawan, Philippines. Journal of Cetacean Research and Management, 6, 4152.

Strindberg, S. \& Buckland, S.T. (2004) Zigzag survey designs in line transect sampling. Journal of Agricultural, Biological, and Environmental Statistics, 9, 443-461.

Strindberg, S., Buckland, S.T. \& Thomas, L. (2004) Design of distance smapling surveys and geographic infromation systems. In: Advanced Distance Sampling (Ed. by S.T. Buckland, D.R. Anderson, K.P. Burnham, J.L. Laake, D.L. Borchers \& L. Thomas), pp. 190-228. Oxford University Press, Oxford, UK.

Taylor, B.L. \& Gerrodette, T. (1993) The uses of statistical power in conservation biology: the vaquita and northern spotted owl. Conservation Biology, 7, 489-500.

Taylor, B.L., Martinez, M., Gerrodette, T. \& Barlow, J. (2007) Lessons from monitoring trends in abundance of marine mammals. Marine Mammal Science, 23, 157-175.

Thomas, L., Sandilands, D. \& Williams, R. (2007) Designing line transect surveys for complex survey regions. Journal of Cetacean Research and Management, 9, 1-11.

Turnock, B.J., Buckland, S.T. \& Boucher, G.C. (1995) Population abundance of Dall's porpoise (Phocoenoides dalli) in the Western North Pacific Ocean. Report of the International Whaling Commission (Spec. Issue), 16, 381-397.

Turvey, S.T., Pitman, R.L., Taylor, B.L., Barlow, J., Akamatsu, T., Barrett, L.A., Zhao, X., Reeves, R.R., Stewart, B.S., Wang, K., Wei, Z., Zhang, X., Pusser, L.T., Richlen, M., Brandon, J.R. \& Wang, D. (2007) First human-caused extinction of a cetacean species? Biology Letters, 3, 537-540.

Van Waerebeek, K., van Bressem, M.-F., Alfaro-Shigueto, J., Sanino, G.P., Montes, D. \& Onton, K. (1999) A preliminary analysis of recent captures of small cetaceans in Peru and Chile. Paper SC/51/SM17 presented to the IWC.

Vidal, O. (1993) Aquatic mammal conservation in Latin America: problems and perspectives. Conservation Biology, 7, 788-795.

Vidal, O., Barlow, J., Hurtado, L.A., Torre, J., Cendon, P. \& Ojeda, Z. (1997) Distribution and abundance of the Amazon river dolphin (Inia geoffrensis) and the tucuxi (Sotalia fluviatilis) in the upper Amazon River. Marine Mammal Science, 13, 427-445. 
Wade, P.R. (1998) Calculating limits to the allowable human-caused mortality of cetaceans and pinnipeds. Marine Mammal Science, 14, 1-37.

Wade, P.R. \& DeMaster, D.P. (1999) Determining the optimum interval for abundance surveys. Marine Mammal Survey and Assessment Methods (Ed. by G.W. Garner, S.C. Amstrup, J.L. Laake, B.J.F. Manly, L.L. McDonald \& D.G. Robertson), pp. 53-66. Balkema, Rotterdam, the Netherlands.

Wade, P.R. \& Gerrodette, T. (1993) Estimates of cetacean abundance and distribution in the eastern tropical Pacific. Report of the International Whaling Commission, 43, 477-493.

Williams, R., Hedley, S.L. \& Hammond, P.S. (2006) Modeling distribution and abundance of Antarctic baleen whales using ships of opportunity. Ecology \& Society, 11, http://www.ecologyandsociety.org/vol77/iss 7/ $\operatorname{art} 7 /$.

Williams, R., Leaper, R., Zerbini, A.N. \& Hammond, P.S. (2007) Methods for investigating measurement error in cetacean line transect surveys. Journal of the Marine Biological Association of the United Kingdom, 87, 313-320.

Wilson, D.L. (2007) David L. Wilson's GPS accuracy web page. Available at: http://users.erols.com/dlwilson/ gpsacc.htm (accessed 29 January 2007).

Zerbini, A.N., Waite, J.M. \& Wade, P.R. (2006) Abundance and distribution of fin, humpback and minke whales from the Kenai Fjords to the Central Aleutian Islands, Alaska: Summer, 2001-03. Deep-Sea Research I, 53, 1772-1790.

Zerbini, A.N., Waite, J.M., Durban, J.W., LeDuc, R., Dahlheim, M.E. \& Wade, P.R. (2007) Estimating abundance of killer whales in the nearshore waters of the Gulf of Alaska and Aleutian Islands using line transect sampling. Marine Biology, 150, 1033-1045.

Submitted 5 November 2007 ; returned for revision 19 December 2007; accepted 28 January 2008 Editor: JD

\section{APPENDIX. USEFUL CALCULATIONS FOR DESIGNING SURVEYS}

An Excel file containing these formulae is available at http://nmml.afsc.noaa.gov/Software/ software.htm. Also available at that site is another Excel file (Geofunc.xla) that provides Excel geometry functions that are useful in survey analysis.

\section{Calculation of effort per unit area}

Sampling effort per unit area represents the sampling intensity of a given survey. As discussed in the text, in a non-stratified survey, different survey blocks should have equal effort per unit area. In a stratified survey, different survey blocks can have unequal effort per unit area. In either case, it is useful to be able to calculate effort per unit area for a given design.

Survey block and transect definitions.

Let (see Fig. 6)

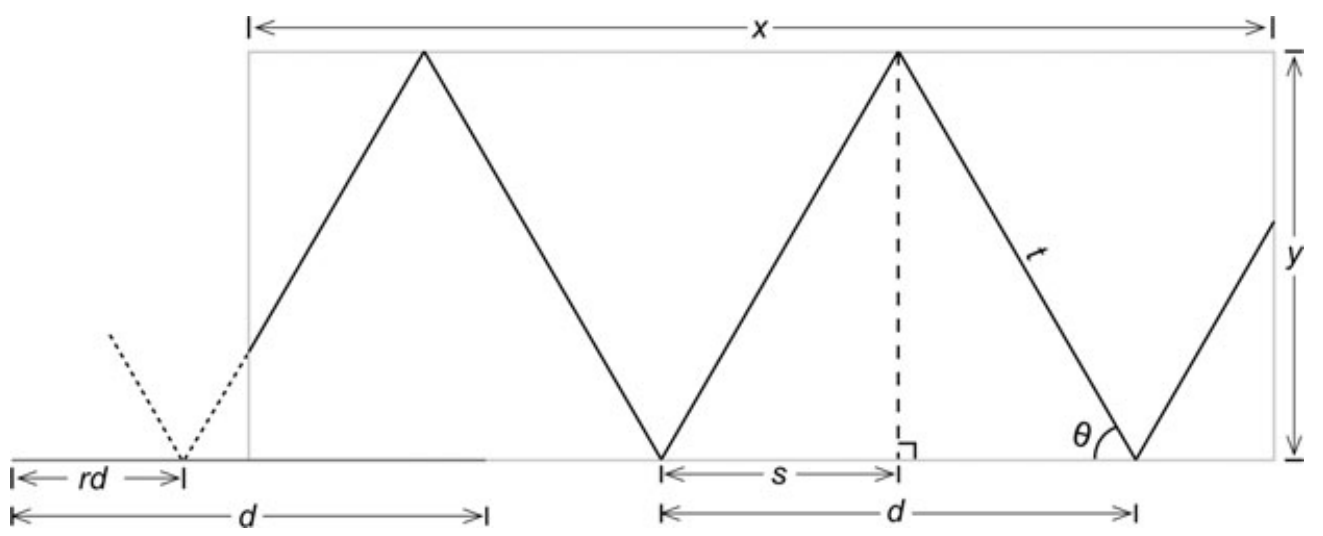

Fig. 6. Figure illustrating terminology used for designing zigzag surveys (see Appendix). 
$a=$ distance between transect lines in a parallel line survey design

$d=$ distance between two apexes in a zigzag survey design

$r d=$ random distance between $s$ and $-s$

$s=0.5 d$, or half the distance between two apexes in a zigzag survey design

$t=$ length of a given transect line (usually spanning the survey block)

$y=$ width of the survey block

$x=$ length of the survey block

a. Parallel lines layout.

For a given spacing between transect lines $(a)$, the effort per unit area is simply the inverse of the distance between the lines:

$$
\frac{\text { Effort }}{\text { Area }}=\frac{1}{a}
$$

(b) Zigzag layout.

For a given zigzag pattern, with survey block of width $y$, with a given distance between the apexes of the zigzag of $d$ (where $s=0.5 d$ ), the effort per unit area is given by:

$$
\frac{\text { Effort }}{\text { Area }}=\frac{t}{s \times y}=\frac{\sqrt{s^{2}+y^{2}}}{s \times y}
$$

Note that there is this relationship between $t, s$, and $y$ :

$$
t=\sqrt{s^{2}+y^{2}}
$$

\section{Calculations of zigzag patterns to meet specified targets.}

Although survey effort per unit area can be specified from statistical calculations to achieve a desired precision (see below), survey design will often be driven by how much boat time is available. In that situation, one can multiply the number of days available for the survey by the survey speed to estimate the amount of track line that can be covered. However, one also has to be realistic about the amount of time that will be lost due to weather or other problems, as well as time spent around animals on closing mode surveys. For example, we have often found it the case that on a survey with 12 hours of daylight, cruising at 10 knots (and thus potentially covering $120 \mathrm{n}$ mile), one can realistically expect to between 60 and $80 \mathrm{n}$ mile per day over the course of a survey. From the predicted total track line that is hoped to be covered with search effort (z), the effort per unit area is simply calculated as total effort divided by the size of the survey block:

$$
\frac{\text { Effort }}{\text { Area }}=\frac{z}{x \times y}
$$

To calculate the correct zigzag pattern from the size of the survey block and the total expected search effort (z), the distance between the apexes $(d)$ can be calculated from:

$$
d=2 \times \sqrt{\frac{y^{2} \times x^{2}}{z^{2}-x^{2}}}
$$

In this way, once $d$ is calculated, the zigzag pattern can then be laid out that will result in a given effort per unit area.

The angle that the transect line is orientated away from shore (where zero degrees would be running parallel to shore) is found by:

$$
\theta=\arctan \left(\frac{y}{s}\right)
$$


To replicate the same effort per unit area in a different sized block, some additional calculations must be made. If the second block is the same width but a different length, the transect lines can be laid out with the same distance between apexes (and will have the same length transects); all that will differ will be the number of individual transects. If the second block has a different width, the following equations can be used to lay out zigzag transect lines that will have the same pre-pecified effort per unit area.

Let the width and length of the 2nd block be designated $y_{2}$ and $x_{2}$, respectively. First, calculate the total transect line needed in the 2 nd block $\left(z_{2}\right)$ to create a specified effort per unit area:

$$
z_{2}=y_{2} \times x_{2} \times\left(\frac{\text { effort }}{\text { area }}\right)
$$

Then calculate the distance between apexes in the 2 nd block $\left(d_{2}\right)$ as:

$$
d_{2}=2 \times \sqrt{\frac{x_{2}^{2} \times y_{2}^{2}}{z_{2}^{2}-x_{2}^{2}}}
$$

\section{Estimating the amount of effort needed to achieve a given level of precision.}

The precision of abundance surveys is often expressed as the coefficient of variation (CV), which is the abundance estimate divided by its estimated standard error. Note that for cetacean line-transect surveys, a rough rule of thumb would be that a CV of 0.10 would be outstanding, 0.30 good, 0.50 fair, and values higher than 0.50 considered poor. If a pilot survey or a similar previous survey has been conducted one can predict the precision of a future survey for a given level of expected sightings or survey effort. This assumes that the future survey will use a similar platform and be conducted in a similar way. If only a small-scale pilot study has been conducted, one can use the number of sightings $\left(n_{0}\right)$ and the total transect length $(L O)$ to calculate the transect length $\left(L_{\text {target }}\right)$ needed to achieve a target coefficient of variation $\left(C V_{\text {target }}\right)$ (Buckland et al., 1993, p. 303):

$$
L_{\text {target }}=\left(\frac{b}{C V_{\text {target }}^{2}}\right) \times\left(\frac{L_{0}}{n_{0}}\right)
$$

Buckland et al.'s (1993) summary of the literature suggests the value of $b$ is fairly stable across surveys, and recommend for planning purposes using a value of 3.0 for $b$ in this equation to be conservative; a value of 2.5 would be more optimistic.

If the CV of abundance (or density) has been calculated from a pilot survey or a similar previous survey, one can estimate $b$ from that previous survey as:

$$
b=n_{0} \times C V^{2}
$$

Then that value of $b$ would be used in Equation 9 rather than an assumed value of 3.0.

If the amount of transect line to be surveyed is prespecified, Equation 9 can be re-arranged to allow one to predict the precision of the future survey for the given level of survey effort using this equation (Buckland et al., 1993):

$$
C V_{\text {expected }}=\left(\frac{b}{L \times\left(\frac{n_{0}}{L_{0}}\right)}\right)^{1 / 2}
$$


Buckland et al. (1993) show this relationship broken down into components of variance from both the number of sightings and from cluster size (e.g. schools of dolphins), but 11 can be used under the assumption that the distribution of cluster sizes will be the same in future surveys as in the previous survey.

\section{Randomizing the start of a transect line}

It is important that the location of the first transect line within a survey block be randomized. Specifically, the transect line should not start in the corner of the survey block (unless randomly picked to start there). One relatively simple way to randomize the first transect line of a zigzag design is to choose a random distance between $s$ and $-s$, and locate the first apex of the zigzag this distance from the corner of the study block. If positive, the first apex is within the survey block. If negative, the first apex is not within the survey block, but simply serves as the starting location of a transect line that will extend into the survey block. Only the portion of the first transect line within the survey block is surveyed. Another way of expressing this is to extend the line representing the length side of the survey block back a distance of $\mathrm{s}$ from the corner of the survey block, then choose a random distance between 0.0 and $d$ $(2 \times s)$ to locate the first apex. In Excel, a function statement to accomplish this, where rd is the random distance between 0.0 and $d$, would be:

$$
r d=d \times R A N D()
$$

Note that RAND() generates a random number between 0.0 and 1.0.

\section{Useful geometry functions}

Many useful geometry functions (written by J. Laake) can also be found at: http:// nmml.afsc.noaa.gov/Software/software.htm in the Excel add-in file geofunc.xla. These include routines for angle and distance measurements (such as calculating a new position a known distance from a given position), geographical position unit conversions, and survey distance measurements (such as calculating distance from reticules in a binocular). 